\title{
Failure of Lightly Reinforced Concrete Members under Fire - Part II: Parametric Studies and Design Considerations
}

\author{
A.Y. Elghazouli ${ }^{1}$ and B.A. Izzuddin ${ }^{2}$
}

\begin{abstract}
This paper deals with the behaviour of lightly reinforced concrete members under fire conditions, focusing on the failure state associated with rupture of the reinforcement. The work transpires from the need to examine the underlying mechanisms related to the failure of composite floor slabs, which become effectively lightly reinforced in a fire situation due to the early loss of the steel deck. The analytical model proposed in the companion paper is utilised to perform a parametric investigation into the salient factors influencing the failure of lightly reinforced restrained members. A detailed account of the analytical results is given, and the relative importance of the main material and geometric parameters is illustrated. It is shown that in addition to temperature effects, the bond characteristics, member length and the steel material response have a direct and significant influence on failure. The implications on structural fire resistance are highlighted, and simplified expressions for failure prediction, which capture the effect of key parameters, are proposed. This work provides a necessary step towards a fundamental methodology which may be employed for developing quantified failure criteria, with a view to the provision of more rational performance based approaches for structural fire design.
\end{abstract}

\footnotetext{
${ }^{1}$ Senior Lecturer in Structural Engineering, Department of Civil and Environmental Engineering, Imperial College, London SW7 2BU, United Kingdom. Member, ASCE.

${ }^{2}$ Reader in Computational Structural Mechanics, Department of Civil and Environmental Engineering, Imperial College, London SW7 2BU, United Kingdom. Member, ASCE.
} 


\section{INTRODUCTION}

There is an ever-increasing recognition of the benefits of adopting performance-based approaches for structural fire design. This is mainly motivated by the need to develop rational design methodologies encompassing appropriately assessed safety margins within a structure. With the growing research interest in this area, there is a move towards improving current codified methods, which are primarily of a prescriptive nature and typically based on individual member assessment through unrealistic fire tests or simple analytical estimations. To this end, most existing code procedures largely fail to account for the interactions that occur between various structural elements at elevated temperatures.

For steel and composite structures, the application of fire protection materials according to available codes has generally led to satisfactory behaviour in normal building fires. In fact, the mounting attention directed to structural fire performance in the last few years has been largely driven by the desire to achieve more cost-effective steel construction by reducing the amount of fire protection in the floor beams (e.g. Johnson, 1998; Robinson, 1998). However, from a more general viewpoint, the main purpose for the advancement of understanding of structural fire response is to improve the rationale of design. Even when fire protection is fully or partially utilised, the assessment of structural behaviour in an extreme loading scenario, in which existing protection could be rendered ineffective, is also necessary.

The structural fire performance of steel buildings with composite steel-concrete floors has been the subject of extensive research investigations in the last few years. A large testing programme was recently completed on a full-scale eight-storey building (Kirby, 1997; O'Connor and Martin, 1998). To complement the results of the fire tests, numerical simulations were carried out by several researchers (e.g. Wang et al, 1995; Huang et al, 1999; Elghazouli and Izzuddin, 2001; Gillie et al, 2001). These research investigations have identified the important role played by the composite floor slab in carrying the gravity loading within the fire compartment, after the loss of strength in the supporting secondary steel beams due to elevated temperature. Moreover, due to the early development of high temperature in the thin steel deck located at the bottom of the composite slab, its contribution 
to the resistance becomes insignificant. As a result, the slab behaves similar to a lightly reinforced concrete (LRC) member with an effective reinforcement mesh that remains at comparatively low temperature. Although the slab exhibits significantly lower bending capacity without the deck, the development of tensile-membrane action coupled with several sources of over-design leads to considerable fire resistance capabilities. (Elghazouli and Izzuddin, 2000).

Before realistic design procedures can be developed for composite floors, it is imperative to provide adequate structural failure criteria as part of an overall fire safety system. Although available non-linear analysis procedures provide good prediction of floor response (Elghazouli and Izzuddin, 2001; Izzuddin et al, 2002), there is a need to determine appropriate failure criteria in order to impose limiting levels of deflection. One of the most important failure criteria is that related to the rupture of reinforcement in the slab, which is accounted for in recent design proposals (Bailey and Moore, 2002-a and 2002-b) in a simple empirical manner independent of important material and geometric properties. For a more realistic representation of failure by reinforcement rupture, it is necessary to adopt a more fundamental approach that accounts for the underlying parameters influencing the behaviour.

In this investigation, the analytical model described in the companion paper (Izzuddin and Elghazouli, 2002) is utilised in a number of parametric studies dealing with the failure of restrained LRC members. The details of the type of member considered in this study are presented, and the main assumptions related to geometric and material properties are discussed. As a necessary basis for fire behaviour, the response is firstly examined under ambient conditions illustrating the influence of the most important parameters. This is followed by an assessment of the member behaviour at elevated temperature considering possible fire effects. Finally, simplified procedures for predicting failure of LRC members are proposed and the implications of the findings on structural fire design are highlighted. 


\section{STRUCTURAL APPLICATION}

Although the work described in this study deals with the behaviour of LRC members in fire from a fundamental perspective, its immediate application is related to composite floors. A typical floor, such as that utilised in recent fire tests (O'Connor and Martin, 1998) is shown schematically in Fig. 1. The composite slab (normally between 2.5 and $4.0 \mathrm{~m}$ span) is supported by secondary steel beams acting compositely with the slab through shear connectors. The conventional design procedure is to treat the short direction of the slab as well as the secondary and primary beams as one-dimensional members supporting the load from the floor. The gravity loading considered in an accidental fire situation typically consists of the unfactored dead load and a proportion of the imposed load.

Depending on the extent of fire spread within compartments as well as the degree of fire protection, some of the steel beams as well as the thin steel deck (typically 0.9-1.2 mm) develop high temperature and become largely ineffective at an early stage. As a result, the slab behaves primarily as a concrete element with light mesh reinforcement, which is required to span over the ineffective steel beams and hence sustain the gravity load from a larger floor area than that intended by design.

Although the flexural capacity of the slab is significantly reduced due to the loss of the steel deck, it is still able to provide considerable fire resistance. This is contributed to by several aspects of floor over-design caused by the idealisation of the member behaviour and support conditions (Elghazouli and Izzuddin, 2000). Most importantly, the slab is usually able to develop tensile membrane action, which significantly increases the load-carrying capacity. The existence of considerable planar restraint in most situations has been demonstrated in earlier studies (Elghazouli and Izzuddin, 2001). In an internal compartment, this is effectively provided by the surrounding cooler structure. On the other hand, in edge compartments, the perimeter beams retain significant stiffness due to their relatively lower temperatures. Besides, the development of a compressive ring in the slab with the presence of adequate reinforcement anchorage contributes to the provision of effective planar restraint (Bailey and Moore, 2002-a). 
The behaviour of a LRC slab is typically characterised by the development of a single crack at the critical section, with failure eventually occurring by fracture of the reinforcement, as illustrated in recent tests (Bailey et al, 2000). This is accounted for in recent design proposals (Bailey and Moore, 2002-b) in an empirical manner due to the absence of a more fundamental failure assessment. Whereas there is ample information on low-reinforcement and bond-slip (e.g. ACI, 1999; EC2, 1996; Park and Paulay, 1975; Bosco et al, 1990), it has mostly focused on serviceability issues related to crack width control and minimum reinforcement levels rather than on ultimate conditions.

The studies presented herein are therefore aimed at providing a basis for assessing failure in axially restrained LRC members by accounting for the influence of key material and geometric parameters. Although the work described in this paper is restricted to onedimensional LRC beam elements, it is believed to be a necessary and significant step towards a full assessment of failure in composite floor slabs under fire. With appropriate consideration of slab equilibrium methods (e.g. Park and Gamble, 2000) such as the simple strip approach, and utilising concepts of integrating component response in fire (Elghazouli and Izzuddin, 2002), it should be possible to generalise the findings of this investigation to other structural and loading configurations.

\section{MEMBER DETAILS}

The analytical model proposed in the companion paper (Izzuddin and Elghazouli, 2002) for LRC members in fire is employed in undertaking parametric studies, focusing on failure by rupture of reinforcement. In this section, the geometric, material and loading details of the restrained LRC member utilised in this investigation are described, and the properties of a reference configuration adopted to facilitate the interpretation of the results are presented.

\section{Geometry and Loading}

As depicted in Fig. 2, the model represents the post-cracking response of an axially-restrained LRC member subject to mid-span loading. The member is simply supported at the level of reinforcement where full axial restraint is provided, as illustrated in Fig. 2-a. The cross- 
section is rectangular, with overall depth (h) and width (b). As shown in Fig. 2-b, a single layer of reinforcement of area $\left(A_{s}\right)$ is located at a prescribed depth $\left(d_{s}\right)$, measured from the bottom concrete fibre. Throughout this study, the centre of rotation is considered at the top concrete fibre, which provides a realistic representation of the behaviour as discussed in the companion paper (Izzuddin and Elghazouli, 2002). Accordingly, the contact depth $\left(\mathrm{h}_{\mathrm{c}}\right)$ may be obtained herein as the difference between $(h)$ and $\left(d_{s}\right)$.

Under fire conditions, the temperature distribution over the cross-section is assumed to be linear. Therefore, bottom and top fibre temperatures, $\left(\mathrm{t}_{\mathrm{b}}\right)$ and $\left(\mathrm{t}_{\mathrm{t}}\right)$ respectively, are specified from the section temperature gradient $(\nabla t)$ and the steel reinforcement temperature $\left(t_{s}\right)$ is determined. No variation in temperature is considered along the length of the member.

In the analysis, only half the simply supported member is considered as illustrated in Fig. 2-c. The analytical model therefore represents a partial-member of length (L) subjected to a vertical load (P) with corresponding deflection (U). Depending on the combination of loading, geometry and material properties, the length (L) will consist of two regions: the bond-slip length $\left(\mathrm{x}_{\mathrm{d}}\right)$ and the no-slip length $\left(\mathrm{L}_{\mathrm{d}}\right)$. It is important to emphasise that at the support end, axial and shear forces are transferred fully to the concrete. This assumption has a direct implication on the relationship between the length of the partial model and the span of the full member in a practical situation.

\section{Material Representation}

The material models utilised in the analysis are described in detail in the companion paper (Izzuddin and Elghazouli, 2002). For the purpose of the discussions presented in this paper, the main material parameters are defined hereafter.

\section{Steel reinforcement}

The commonly used Ramberg-Osgood model is employed for the steel reinforcement, hence providing a single stress-strain relationship throughout the elasto-plastic range. The model relates the mechanical strain $\left(\varepsilon_{\mathrm{sm}}\right)$ to the stress $\left(\sigma_{\mathrm{s}}\right)$ as follows: 


$$
\varepsilon_{\mathrm{sm}}=\frac{\sigma_{\mathrm{s}}}{\mathrm{E}_{\mathrm{s}}}+\mathrm{a}_{\mathrm{s}} \sigma_{\mathrm{s}}^{\mathrm{n}_{\mathrm{s}}}
$$

where $E_{s}$ is the elastic Young's modulus, and $a_{s}$ and $n_{s}$ are the two constants which affect the elasto-plastic response.

Under elevated temperature, the total strain in the steel $\left(\varepsilon_{\mathrm{s}}\right)$ includes the thermal strain $\left(\varepsilon_{\mathrm{st}}\right)$, which is evaluated using a constant coefficient of thermal expansion $\left(\alpha_{s}\right)$ such that:

$$
\begin{aligned}
& \varepsilon_{\mathrm{s}}=\varepsilon_{\mathrm{sm}}+\varepsilon_{\mathrm{st}} \\
& \varepsilon_{\mathrm{st}}=\alpha_{\mathrm{s}} \mathrm{t}_{\mathrm{s}}
\end{aligned}
$$

The influence of elevated temperature on the steel material is considered by varying $\mathrm{E}_{\mathrm{s}}$, $\mathrm{a}_{\mathrm{s}}$ and $\alpha_{\mathrm{s}}$ with the steel temperature $\left(\mathrm{t}_{\mathrm{s}}\right)$ through piecewise trilinear curves

\section{Concrete}

As the model is intended for the post-cracking response following the formation of a single mid-span crack, and on the assumption that concrete remains within its compressive strength, the response of concrete is assumed to be linear elastic. However, the influence of elevated concrete temperature $\left(t_{c}\right)$ on the elastic modulus $\left(E_{c}\right)$ and on the thermal strain $\left(\varepsilon_{c t}\right)$ is accounted for such that:

$$
\begin{aligned}
& \varepsilon_{\mathrm{c}}=\varepsilon_{\mathrm{cm}}+\varepsilon_{\mathrm{ct}} \\
& \varepsilon_{\mathrm{cm}}=\frac{\sigma_{\mathrm{c}}}{\mathrm{E}_{\mathrm{c}}} \\
& \varepsilon_{\mathrm{ct}}=\alpha_{\mathrm{c}} \mathrm{t}_{\mathrm{c}}
\end{aligned}
$$

where, $\varepsilon_{\mathrm{cm}}$ is the concrete mechanical strain, $\alpha_{\mathrm{c}}$ is the coefficient of thermal expansion, and $E_{c}$ is assumed to vary with $t_{c}$ according to a piecewise trilinear curve.

\section{Bond-slip}

Given the lightly-reinforced nature of the member, the influence of bond-slip on the overall member response, leading to the ultimate failure state, is approximated using a rigid-plastic relationship. Consequently, only the bond strength $\left(\sigma_{b}\right)$ is required, which is defined here as 
the maximum bond force per unit length, thus encapsulating the effects of the maximum bond stress and the cumulative reinforcement bar diameters. Similar to other material parameters, the variation of $\sigma_{b}$ with temperature at the steel/concrete interface $\left(t_{s}\right)$ is assumed to follow a piecewise trilinear curve.

\section{Reference Case}

In order to provide a basis for the parametric studies and to facilitate the interpretation of results, reference properties are selected for a LRC member and used as a control configuration. Thereafter, in the parametric investigation, one or more properties are varied whilst retaining the values of the other parameters.

The dimensional and material properties used for the reference model are summarised in Table 1 . The parameters of this model are chosen such that they are generally representative of a one-dimensional strip from the concrete part of typical composite slab (Elghazouli and Izzuddin, 2001). Nevertheless, it should be recalled that the main purpose of this investigation is to gain insight into the factors influencing failure rather than faithful characterisation of a specific configuration.

The length (L) used in the control model is selected as $1.5 \mathrm{~m}$ which, depending on continuity and support conditions, may be generally considered to represent a one-dimensional member with an effective span of between $2 \mathrm{~L}$ and $4 \mathrm{~L}$. The bond strength $\left(\sigma_{\mathrm{b}}\right)$, which is the product of the reinforcement surface area per unit length and the maximum bond stress, is assumed as $40 \mathrm{~N} / \mathrm{mm}$ for the reference case at ambient temperature conditions. The reinforcement prescribed is such that the steel-to-concrete area ratio $(\rho)$ is $0.25 \%$, with the reinforcement considered at mid-depth of the cross-section.

In terms of the ambient stress-strain relationship of steel, the constants $\mathrm{a}_{\mathrm{s}}$ and $\mathrm{n}_{\mathrm{s}}$ employed in (1) are assumed as 5.3E-71 and 25, respectively, and the ultimate plastic strain at failure $\left(\varepsilon_{\mathrm{pu}}\right)$ is considered as $15 \%$. These values result in a corresponding ultimate stress $\left(\sigma_{\mathrm{u}}\right)$ of 600 $\mathrm{N} / \mathrm{mm}^{2}$ and a proof stress $\left(\sigma_{0.2}\right)$, at $0.2 \%$ plastic strain, of $505 \mathrm{~N} / \mathrm{mm}^{2}$. 
In subsequent sections of this paper, results obtained from a number of sensitivity and parametric examinations are presented and their implication on structural fire resistance design are highlighted.

\section{AMBIENT RESPONSE}

Before examining the response at elevated temperature, it is imperative to gain insight into the behaviour at ambient conditions. An initial analysis using the reference model is first presented and discussed. This is followed by an assessment of the main parameters influencing the behaviour, which include the stress-strain relationship for steel, bond characteristics, cross-section depth and member length.

\section{Control Analysis}

Using the reference model described in the previous section, an initial analysis is carried out to act as a basis for the parametric investigation. In the analysis, the tensile force in the steel reinforcement $\left(\mathrm{T}_{\mathrm{s}}\right)$ is incrementally increased until failure is reached upon the development of an ultimate tensile force $\left(\mathrm{T}_{\mathrm{su}}\right)$ corresponding to $\sigma_{\mathrm{u}}$. Fig. 3 depicts the response of the control member obtained from the detailed version of the analytical model as well as the more simplified approach, the latter dealing only with the tensile catenary stage (Izzuddin and Elghazouli, 2002).

In Fig. 3-a, the vertical load (P) is plotted against the deflection (U) up to the point of reinforcement fracture. It is evident that accounting for the compressive arch stage initially has a significant influence on the behaviour. As the deflection level approaches the depth of the section, the compressive effect gradually disappears and tensile catenary action becomes dominant, with the two approaches providing nominally identical response thereafter. If failure is reached at a deflection level exceeding the compressive range, which is the case in this control analysis, it would be appropriate to employ the simplified approach for assessing the ultimate response in terms of both load and deflection levels. It is also important to note that even when failure occurs within the compressive arching stage, the simplified approach still predicts the ultimate deflection reasonably well, though not the failure load. 
Fig. 3-b shows the relationship between the bond-slip length $\left(\mathrm{x}_{\mathrm{d}}\right)$ and the vertical deflection (U). The slip length increases gradually with deflection and corresponds to about $30 \%$ of the overall length (L) at failure. On the other hand, Fig. 3-c depicts the relationship between the stress in the steel reinforcement $\left(\sigma_{\mathrm{s}}\right)$ at mid-span (i.e. at the crack) and the deflection (U). Again, it is clear that for a deflection exceeding the depth of the section, the results of the two analytical approaches coincide.

The local strains in concrete are monitored across the section and along the member length in order to ensure that they remain within the range of validity. For the control analysis, the maximum compressive stress reached at the assumed centre of rotation, is about $15 \mathrm{~N} / \mathrm{mm}^{2}$, which is well below the expected crushing strength. In this respect, the assumption that the centre of rotation lies at the top fibre represents the most severe condition.

In the control case, the tensile stress in concrete within the no-slip region at the point of failure is below $1.5 \mathrm{~N} / \mathrm{mm}^{2}$, which is lower than the typical splitting strength of concrete, hence additional full-depth cracks would not normally develop during the tensile catenary range. Consequently, failure is assumed to occur by fracture of reinforcement, at the location of the initial crack, when the local strain at this point reaches the assumed ultimate plastic strain $\left(\varepsilon_{\mathrm{pu}}\right)$ of $15 \%$. It is also noteworthy that, for the control case, the failure point corresponds to an estimated average strain $\left(\varepsilon_{\mathrm{vm}}\right)$ the steel reinforcement of about $0.2 \%$. This indicates that the strain localisation in the steel at the crack exceeds 70 times the average value over the length, which is an important conclusion for assessment purposes as discussed in subsequent parts of this paper.

\section{Steel Constitutive Relationship}

The shape of the constitutive relationship of steel may vary significantly depending on the type and grade of reinforcement used. In addition to the fracture strain of the reinforcement, the stress-strain relationship employed for steel has a significant influence on the ultimate behaviour. To illustrate this, the parameters of the constitutive law described in (1) are varied, whilst retaining the same value of ultimate strain and corresponding ultimate stress. The three 
variations considered for the steel material law are described in Table 2 and depicted in Fig. 4-a, reflecting different types of reinforcement.

The relationships between load and deflection for the three steel materials considered are shown in Fig. 4-b. It is evident that, whereas the response curves are of similar shape in all three cases, failure is significantly delayed if the material exhibits relatively higher strain hardening properties. This effect is illustrated further by observing the extent of the slip length $\left(\mathrm{x}_{\mathrm{d}}\right)$ for all three cases, as shown in Fig. 4-c. Although the ultimate slip length at failure is the same, it is mobilised at a relatively low level of deflection when strain hardening is insignificant, as in the case of the control model, hence leading to early failure. It is also important to note that the maximum compressive as well as the ultimate tensile stresses attained in concrete (which occur during the compressive arching stage) are not significantly affected by the variation in the shape of the steel constitutive relationship.

From the above discussion, it is clear that with relative increase in effective strain hardening, the localisation of strain in the reinforcement at the crack is reduced, hence increasing the load-carrying and deformation capacity of the member. Comparing the three types selected, the strain concentration in the reinforcement at the crack reduces from over 70 for Type $S 1$ to about 20 for Type S3. It follows that an adequate representation of the constitutive relationship of the reinforcement steel is imperative for a proper assessment of failure in an axially-restrained LRC member.

\section{Bond Characteristics}

The bond strength between the steel reinforcement and the surrounding concrete is one of the most important parameters influencing the behaviour. In practice, the bond properties may vary considerably depending on the type and surface condition of the reinforcement as well as the properties of the surrounding concrete. This is examined here by assessing the response employing various values of $\sigma_{b}$ between 10 and $120 \mathrm{~N} / \mathrm{mm}$, whilst retaining all the other parameters of the control model. 
The load versus deflection curves for the various cases considered are depicted in Fig. 5-a. Evidently, the bond strength has some effect on the load-deflection response, but more importantly it has a pronounced influence on the failure level. For relatively high $\sigma_{\mathrm{b}}$, in excess of $100 \mathrm{~N} / \mathrm{mm}$, failure occurs in the compressive arch stage, at deflections smaller than the section depth. In such situations, and since failure occurs prior to the transition to tensile catenary action, the simplified analytical approach in which the compressive stage is ignored would not accurately predict the failure load.

The variation of the slip length with deflection for the various values of $\sigma_{b}$ is depicted in Fig. 5-b. Clearly, the slip length becomes larger as the bond decreases, even reaching the full length of the member for an extremely low bond strength, leading to considerable delay of reinforcement rupture. Consequently, the strain concentration in the reinforcement at rupture is directly related to $\sigma_{\mathrm{b}}$, being lower than 20 for $\sigma_{\mathrm{b}}$ of $10 \mathrm{~N} / \mathrm{mm}$ and increasing to more than 200 for $\sigma_{\mathrm{b}}$ of $120 \mathrm{~N} / \mathrm{mm}$. This implies that low bond can lead to a beneficial delay in the fracture of reinforcement and to a corresponding enhancement of the capacity, contrary to other normal design situations in which high bond is desirable.

\section{Reinforcement Ratio}

It is important to examine the influence of the reinforcement ratio on the response as well as the range of validity of the analysis. Since the bond characteristics are directly related to the area of steel, variation of the reinforcement ratio is coupled with a proportional modification of the bond strength. Several values of $\rho$ between $0.05 \%$ and $1.0 \%$ are adopted, with corresponding values of $\sigma_{\mathrm{b}}$ between 8 and $160 \mathrm{~N} / \mathrm{mm}$, respectively.

The load-deflection response for various $\rho$ values is shown in Fig. 6-a, whereas the slip length versus deflection is depicted in Fig. 6-b. Unlike the load-carrying capacity, the deflection at failure is not significantly influenced by the variation in $\rho$. The increase in the steel force for higher reinforcement areas is largely balanced by the enhanced bond strength, causing only a marginal modification to the slip length. 
With the increase in $\rho$, the maximum compressive stress in concrete within the compressive arching range increases. However, this remains well below the compressive strength of concrete. On the other hand, for high $\rho$ ratios, the tensile stress in concrete at ultimate deflection may well exceed the tensile strength. The tensile stress obtained within the nonslip region at the ultimate state is directly proportional to $\rho$. In this study, the concrete tensile stress at ultimate varied between $0.3 \mathrm{~N} / \mathrm{mm}^{2}$ to almost $6.0 \mathrm{~N} / \mathrm{mm}^{2}$ for the corresponding $\rho$ values of 0.05 and $1.0 \%$, respectively. This implies that, for the configuration considered herein, the results are typically valid up to a reinforcement ratio of about $0.8 \%$. Beyond this ratio, additional full-depth cracks may develop in the tensile catenary range, and the assessment of failure deflection and load becomes increasingly conservative.

\section{Cross-Section Depth}

The influence of varying the depth of the cross-section is examined by modifying parameters used in the control model. In order to isolate the effect of the depth on the attained response, the reinforcement ratio of the control model is retained by changing the steel area together with the bond strength. As in the case of the control model, the reinforcement is located at mid-depth. The parameters used in the study are summarised in Table 3, whilst all other properties of the control model remain unchanged.

Figs. 7-a and 7-b depict the load versus deflection and slip length versus deflection relationships, respectively. As expected, the effective variation in $h_{c}$ has a significant influence on the response within the initial compressive stage. The increase in depth causes an enhancement of the compressive arch effect, which is directly related to the member depth or, more importantly, to the contact depth $\left(h_{c}\right)$. It is also evident that for relatively deep members, specifically more than $100 \mathrm{~mm}$ in this case, failure may occur within the compressive stage and prior to the effective commencement of the tensile catenary action.

With the increase in depth, the stresses in concrete during the compression stage increase in turn but remain below typical values of compressive strength. The initial compression in concrete is gradually released as the deflection increases, accompanied by loss of arching contact. It should be noted that the behavioural aspects discussed in this section also largely 
apply to the influence of varying the reinforcement location $\left(d_{s}\right)$ within a constant section height $(\mathrm{h})$, as this is coupled with a direct modification of the contact depth $\left(\mathrm{h}_{\mathrm{c}}\right)$.

\section{Member Length}

The length of the member has a significant effect on the response in both the compressive arch and tensile catenary stages. In order to illustrate this influence, the partial member length (L) is varied between 1.0 and $3.0 \mathrm{~m}$, retaining the other details of the control model.

The resulting vertical load-deflection response for this study is depicted in Fig. 8-a, whilst the slip length versus deflection is shown in Fig. 8-b. Clearly, the slip length attained at failure does not change significantly with L. It is also evident that for a relatively short member, the sustained vertical load within the compressive stage is comparatively large due to the increase in bending and axial stiffness. As discussed previously, the deflection level beyond which compressive contact is lost is not sensitive to the member length variation as it is mainly related to the cross-section depth.

Whereas the tensile stress in concrete in the no-slip region at failure is not influenced by L, the maximum compressive concrete stress within the compressive stage increases for a shorter length. However, for the range considered in this study, this stress remains well below the compressive strength of concrete. On the other hand, the strain concentration ratio in the steel reinforcement at failure increases with the increase in length. This factor is about 25 for $\mathrm{L}$ of $1.0 \mathrm{~m}$ and increases proportionally to 140 for $\mathrm{L}$ of $3.0 \mathrm{~m}$. This relatively high localisation of strain in longer member is a direct consequence of the effective increase in the ratio between the overall length and the extent of the slip zone.

The results provided in this section illustrate the influence of salient parameters on the behaviour. As discussed above, these include a number of geometric and material properties. For a rational examination of failure, these factors should be appropriately accounted for within a structural assessment approach for axially-restrained LRC members. In addition to the effects treated above, other considerations also need to be incorporated if the member is subject to elevated temperature, as discussed in the following section. 


\section{ELEVATED TEMPERATURE RESPONSE}

Under fire conditions, the structural member is subjected to elevated temperature, which influences the response through the degradation in material properties in addition to the effects of thermal expansion and thermal curvature. Hereafter, the temperature-dependent properties adopted in this study are presented, and the behaviour of the control model is examined under various idealised fire situations.

\section{Material Properties}

The control model described in Table 1 is utilised in this section to illustrate the behaviour under elevated temperature. The influence of temperature on the steel and concrete material properties is summarised in Table 4 , where $\mathrm{E}_{\mathrm{s}}, \mathrm{E}_{\mathrm{c}}, \sigma_{\mathrm{b}}$ and $\sigma_{\mathrm{u}}$ at elevated temperature are presented as ratios of their respective values at ambient conditions. Piecewise linear interpolation is used for temperatures between the values indicated in Table 4.

The stress-mechanical strain relationship for steel, given in (1), is defined at an elevated temperature by considering $\mathrm{E}_{\mathrm{s}}$ and $\mathrm{a}_{\mathrm{s}}$ to vary with the steel temperature $\left(\mathrm{t}_{\mathrm{s}}\right)$. The variation of $a_{\mathrm{s}}$ with temperature is established in terms of $\sigma_{\mathrm{u}}$, as follows:

$$
\mathrm{a}_{\mathrm{s}}=\frac{\varepsilon_{\mathrm{pu}}}{\sigma_{\mathrm{u}}^{\mathrm{ns}}}
$$

whilst $\mathrm{E}_{\mathrm{s}}$ and $\sigma_{\mathrm{u}}$ are obtained at any specific temperature by adopting the properties assumed in Table 4.

It should be noted that the properties presented in Table 4 represent tri-linear idealisation of available information on temperature-dependent material behaviour (e.g. Neville, 1995; Buchanan, 2001; Royles et al, 1982; Sager and Rostasy, 1982; EC4, 1995). These properties may, however, vary considerably depending on the specific type of reinforcement and concrete material used. It is therefore imperative to determine the actual temperaturedependent properties of the constituent materials if an accurate quantitative response assessment is sought for a specific case. To this end, the purpose of the discussions presented in this section is to highlight the general behavioural trends and the relative influence of the main parameters considered to be of most importance. 


\section{Thermal Effects}

The control model, described in Table 1, is utilised and the temperature-dependent material properties given in Table 4 are adopted. A general case is initially examined in which a linear temperature gradient is assumed within the cross-section, simulating idealised fire conditions. The bottom temperature $\left(t_{b}\right)$ is prescribed whilst the top fibre remains at ambient conditions (i.e. $\mathrm{t}_{\mathrm{t}}=0$ ). For steel, $\alpha_{\mathrm{s}}$ is considered as $14 \times 10^{-6}$, whilst $\alpha_{\mathrm{c}}$ is assumed as $8 \times 10^{-6}$ representing a light weight material.

The results described below are obtained from the detailed version of the analytical model presented in the companion paper (Izzuddin and Elghazouli, 2002). However, it should be noted that the response obtained from the simplified version, which considers the tensile catenary stage only, is almost identical to that of the detailed model. Discrepancies only occur at initial stages of loading under low temperatures, where the compressive arch action may be present. Importantly, even when failure occurs within the compressive stage, the simplified model still predicts the failure deflection with reasonable accuracy.

The load-deflection curves for various $t_{b}$ are shown in Fig. 9-a, whilst the slip length versus deflection is given in Fig. 9-b. It is evident that the response is significantly influenced by the increase in temperature, in terms of the initial and ultimate deflection, failure load, maximum slip length as well as the overall response history. Most notably, the increase in temperature causes the member to buckle and deform due to restrained thermal expansion, as observed in earlier investigations (Elghazouli and Izzuddin, 2000), which explains the initial deflections at low levels of loads.

Clearly, there are a number of inter-related parameters that affect the behaviour at elevated temperature including the variation in material properties, thermal expansion and thermal curvature. Since the emphasis in this investigation is on the assessment of failure, further examination of the ultimate state is carried out by modifying some of the parameters used in the previous analysis. Four cases are considered as follows:

(i) Gradient $\left(t_{b}, t_{t}=0\right)$, unequal coefficients of expansion $\left(\alpha_{s}=14 \times 10^{-6}, \alpha_{c}=8 \times 10^{-6}\right)$

(ii) Gradient $\left(t_{b}, t_{t}=0\right)$, equal coefficients of expansion $\left(\alpha_{s}=\alpha_{c}=14 \times 10^{-6}\right)$ 
(iii) No gradient $\left(t_{b}=t_{t}\right)$, unequal coefficients of expansion $\left(\alpha_{s}=14 \times 10^{-6}, \alpha_{c}=8 \times 10^{-6}\right)$

(iv) No gradient $\left(t_{b}=t_{t}\right)$, equal coefficients of expansion $\left(\alpha_{s}=\alpha_{c}=14 \times 10^{-6}\right)$

Figs. 10-a, 10-b and 10-c depict the load, deflection and slip length, respectively, at failure, for the above four cases. Since the temperature attained in the steel reinforcement has the most significant influence on the response, the results are presented in terms of $t_{\mathrm{s}}$. As shown in Fig. 10-a, the failure load initially increases with the increase in $t_{s}$ for all four cases, primarily due to thermal expansion coupled with geometric effects. Starting from $400^{\circ} \mathrm{C}$, the reduction in steel strength causes a gradual decline in the failure load. The failure deflection, depicted in Fig. 10-b, clearly illustrates the influence of thermal gradient and thermal expansion. Due to thermal curvature (bowing), the failure deflection is relatively low when a gradient is present within the section. On the other hand, the slip length at failure, shown in Fig. 10-c, is sensitive to the difference in the thermal expansion properties of the two constituent materials. For cases (i) and (iii), in which $\alpha_{s}$ is larger than $\alpha_{c}$, the slip length at failure is consistently higher than in cases (ii) and (iv) in which $\alpha_{s}=\alpha_{c}$, which indicates the influence of the differential steel/concrete thermal expansion. As expected, in addition to thermal gradient and the variation of material properties with temperature, the change of the slip length at failure with temperature has a direct effect on the failure load and corresponding deflection.

Throughout the results presented above, it is assumed that additional full-depth cracks do not develop within the concrete section during the tensile catenary stage. This condition is verified by monitoring the tensile strains in concrete. Although the tensile strength of concrete reduces with the increase in temperature, this is counter-balanced by the significant increase in concrete strain at failure, hence preventing the opening of additional cracks. Nevertheless, although the single crack assumption is generally conservative, as discussed in the companion paper (Izzuddin and Elghazouli, 2002), this is an issue that requires further experimental examination, particularly for parameter ranges beyond those considered within the scope of this study. 


\section{FAILURE PREDICTION}

The observations and conclusions drawn from the above parametric investigations are utilised in this section for a more focused examination of the ultimate conditions. Additionally, for the benefit of future design-related studies, simple procedures and direct expressions for predicting failure in restrained LRC members are suggested and discussed. As the emphasis here is on assessing failure deflection rather than on simulating the detailed response history, the more efficient simplified version of the analytical model presented in the companion paper (Izzuddin and Elghazouli, 2002) is employed.

\section{Ambient Conditions}

Assessment of failure at an ambient state is a significant precursor towards providing an understanding of the behaviour at elevated temperature. In this section, the strain and deflection levels at failure are examined and the main factors affecting them are highlighted.

\section{Ultimate State}

Failure occurs when the stress in the steel at the crack location reaches $\sigma_{u}$ corresponding to $\varepsilon_{\mathrm{pu}}$. The force in the steel reinforcement at failure is denoted by $\mathrm{T}_{\mathrm{su}}$ which represents the product of $A_{s}$ and $\sigma_{u}$, such that:

$$
\mathrm{T}_{\mathrm{su}}=\mathrm{A}_{\mathrm{s}}\left(\frac{\varepsilon_{\mathrm{pu}}}{\mathrm{a}_{\mathrm{s}}}\right)^{1 / \mathrm{n}_{\mathrm{s}}}
$$

Within the no-slip region, the strain along the reference line of the reinforcement $\left(\varepsilon_{\text {an }}\right)$ can be determined directly from the equations given in the simplified analytical model of the companion paper (Izzuddin and Elghazouli, 2002), by replacing $\mathrm{T}_{\mathrm{s}}$ with $\mathrm{T}_{\mathrm{su}}$. Clearly, $\varepsilon_{\mathrm{an}}$ and more generally, the extreme fibre strain within this region, should not exceed the ultimate tensile strain of concrete. Otherwise, the single crack assumption of the LRC member becomes increasingly conservative.

Based on $\varepsilon_{\mathrm{sn}}$, the steel stress in the no-slip region is obtained as:

$$
\sigma_{\mathrm{sn}}=\mathrm{E}_{\mathrm{s}} \varepsilon_{\mathrm{an}}
$$

and the slip length of the member at failure is then determined as follows: 


$$
\mathrm{x}_{\mathrm{d}}=\frac{\mathrm{T}_{\mathrm{su}}-\mathrm{A}_{\mathrm{s}} \sigma_{\mathrm{sn}}}{\sigma_{\mathrm{b}}} \quad \text { with } \mathrm{x}_{\mathrm{d}} \leq \mathrm{L}
$$

By employing the steel stress-strain relationship of (1), the extension of steel $\left(\Delta_{\mathrm{s}}\right)$ at failure can be derived explicitly as:

$$
\Delta_{\mathrm{s}}=\left[\frac{1}{2 \mathrm{E}_{\mathrm{s}}}\left(\frac{\mathrm{T}_{\mathrm{su}}+\mathrm{A}_{\mathrm{s}} \sigma_{\mathrm{sn}}}{\mathrm{A}_{\mathrm{s}}}\right)+\mathrm{a}_{\mathrm{s}} \frac{\mathrm{T}_{\mathrm{su}}^{\mathrm{n}_{\mathrm{s}}+1}-\left(\mathrm{A}_{\mathrm{s}} \sigma_{\mathrm{sn}}\right)^{\mathrm{n}_{\mathrm{s}}+1}}{\left(\mathrm{n}_{\mathrm{s}}+1\right)\left(\mathrm{T}_{\mathrm{su}}-\mathrm{A}_{\mathrm{s}} \sigma_{\mathrm{sn}}\right) \mathrm{A}_{\mathrm{s}}^{\mathrm{n}_{\mathrm{s}}}}\right] \mathrm{x}_{\mathrm{d}}+\varepsilon_{\mathrm{an}}\left(\mathrm{L}-\mathrm{x}_{\mathrm{d}}\right)
$$

based on which the deflection (U) at failure is determined as:

$$
\mathrm{U}=\sqrt{\left(\mathrm{L}+\Delta_{\mathrm{s}}\right)^{2}-\mathrm{L}^{2}}
$$

Provided that failure occurs in the tensile catenary range, which would be the case if $U$ from (12) is larger than the section depth (h), then the load at failure may simply be deduced as:

$$
\mathrm{P}=\frac{\mathrm{U}}{\mathrm{L}+\Delta_{\mathrm{s}}} \mathrm{T}_{\mathrm{su}}
$$

The above equations provide an explicit procedure for evaluating the ambient failure deflection of restrained LRC members of the form considered in this study. Further design simplification may be applied to this procedure as discussed in the following section.

\section{Reduced Expressions}

For design purposes, it would be useful to provide predictions for the deflection and strain levels corresponding to failure, preferably through simple expressions that encompass the key parameters. By close examination of (8) to (12), and in view of the discussions made in the parametric studies, it is evident that the bond characteristics and the length, as well as the stress-strain relationship for the steel reinforcement, play a most significant role in determining the failure point.

Following from the above, and within practical ranges of material and geometric parameters, it becomes clear that the average strain at failure $\left(\varepsilon_{\mathrm{vm}}\right)$ and, equivalently, the deflection $(\mathrm{U})$ at failure are intimately related to a number of important parameters. This is illustrated in Fig. 11-a which depicts the strain concentration of the steel at the crack, defined as the ratio of

ultimate strain $\left(\varepsilon_{\mathrm{um}}\right)$ to the average strain at failure $\left(\varepsilon_{\mathrm{vm}}\right)$, and through Fig. 11-b which 
assesses the failure deflection as a proportion of the length (U/L). In the above, $\varepsilon_{\mathrm{vm}}$ and $\varepsilon_{\mathrm{um}}$ are determined as:

$$
\varepsilon_{\mathrm{vm}}=\frac{\Delta_{\mathrm{s}}}{\mathrm{L}}
$$

and

$$
\varepsilon_{\mathrm{um}}=\frac{\sigma_{\mathrm{u}}}{\mathrm{E}_{\mathrm{s}}}+\varepsilon_{\mathrm{pu}}
$$

The data set used in Fig. 11 represents the results of (8) to (12) for an illustrative range of parameters, with various lengths and bond strengths for three $\rho$ values of $0.125 \%, 0.25 \%$ and $0.5 \%$, and using the three steel types described in Table 2 .

Fig. 12-a indicates that, within the practical parameter range considered, the strain concentration $\left(\varepsilon_{\mathrm{um}} / \varepsilon_{\mathrm{vm}}\right)$ is directly related to a non-dimensional parameter $\left(\beta_{\varepsilon}\right)$ defined as:

$$
\beta_{\varepsilon}=\frac{\sigma_{\mathrm{b}} \mathrm{L}}{\mathrm{A}_{\mathrm{s}}\left(\sigma_{\mathrm{u}}-\sigma_{0.2}\right)}
$$

As evident in the figure, the relationship between $\varepsilon_{\mathrm{um}} / \varepsilon_{\mathrm{vm}}$ and $\beta_{\varepsilon}$ is closely linear with the concentration being about three-times of $\beta_{\varepsilon}$. This linear relationship may be easily adjusted to reflect $\varepsilon_{\mathrm{um}} / \varepsilon_{\mathrm{vm}}$ of unity for zero bond strength, but is not considered practically necessary. It should also be noted that this linear relationship does not apply outside practical parameter ranges, particularly for unrealistically low bond strength in very short members for which the slip length may be limited by the member length.

It is clear from Fig. 11-a and (16), that the strain concentration $\left(\varepsilon_{\mathrm{um}} / \varepsilon_{\mathrm{vm}}\right)$ can reach extremely high values, leading to exceptionally low average strain at failure. The value of $\varepsilon_{\mathrm{um}} / \varepsilon_{\mathrm{vm}}$ is dependent on the bond strength, the member length, the steel area and the post-proof stress range. It directly increases with the increase of $\sigma_{b}$ and $L$, and reduces with $A_{s}$. Moreover, failure is considerably delayed when a steel material with relatively high steel hardening is utilised, as reflected here by the balance between $\sigma_{\mathrm{u}}$ and $\sigma_{0.2}$. 
For the loading configuration considered in this study, and as illustrated in Fig. 11-b, it is also possible to establish a direct relationship between the normalised deflection (U/L) at failure and a parameter $\left(\psi_{\mathrm{U}}\right)$ given by:

$$
\psi_{\mathrm{U}}=\sqrt{\frac{\mathrm{A}_{\mathrm{s}}\left(\sigma_{\mathrm{u}}-\sigma_{0.2}\right)}{\sigma_{\mathrm{b}} \mathrm{L}} \varepsilon_{\mathrm{um}}}=\sqrt{\frac{\varepsilon_{\mathrm{um}}}{\beta_{\varepsilon}}}
$$

As shown in Fig. 12-b, the relationship between U/L and $\psi_{\mathrm{U}}$ is approximately linear with a slope of about $\sqrt{2 / 3}$ which may be independently derived from (16) and the appropriate transformation between average strain and deflection.

Clearly, from (17) and Fig. 11-b, the normalised deflection at failure is non-linearly and inversely related to $\beta_{\varepsilon}$. The normalised failure deflection is evidently enhanced with the increase in effective strain hardening as well as ultimate strain, whereas it is reduced with higher $\sigma_{\mathrm{b}}$ and L. To this end, recently proposed design expressions (Bailey and Moore, 2000b) imply a constant value of U/L irrespective of other factors, which can admittedly be scaled down to provide a largely conservative estimate. A more realistic failure prediction can be achieved by adopting the relationship between $\mathrm{U} / \mathrm{L}$ and $\left(\psi_{\mathrm{U}}\right)$ based on the findings of this work as it captures the influence of key material and geometric parameters.

\section{Elevated Temperature}

As discussed previously, elevated temperatures influence the response of a member through the reduction of material properties as well as thermal expansion and thermal curvature. Even for a simple structural configuration, the behaviour may be relatively complex. The analytical model presented in the companion paper (Izzuddin and Elghazouli, 2002) can be used to simulate the member behaviour. Additionally, the simplified version that employs a conveniently explicit procedure can be utilised for further analytical and design studies. In this section, further simplifications leading to a single expression for estimating the failure deflection, are suggested in an effort towards combining adequate failure prediction with a reduced set of calculations. 


\section{Ultimate Conditions}

Based on the simplified version of the analytical model (Izzuddin and Elghazouli, 2002) for the loading configuration considered, the failure deflection is given as:

$$
\mathrm{U}=\sqrt{\left(\mathrm{L}-\delta_{\mathrm{c} 0}+\Delta_{\mathrm{s}}\right)^{2}-\mathrm{L}^{2}}
$$

where $\Delta_{\mathrm{s}}$ is the steel extension at ultimate with due account for thermal effects and $\delta_{\mathrm{c} 0}$ represents the axial pull-in due to unrestrained thermal bowing given by:

$$
\delta_{\mathrm{c} 0}=\frac{\theta_{\mathrm{t} 0}^{2} \mathrm{~L}}{6}
$$

in which:

$$
\theta_{\mathrm{t} 0}=-\alpha_{\mathrm{c}} \nabla \mathrm{t} \mathrm{L} / 2
$$

If conditions are satisfied for failure to occur in the tensile catenary range (Izzuddin and Elghazouli, 2002), the ultimate load may also be obtained from:

$$
\mathrm{P}=\frac{\mathrm{U}}{\mathrm{L}-\delta_{\mathrm{c} 0}+\Delta_{\mathrm{s}}} \mathrm{T}_{\mathrm{su}}
$$

where $\mathrm{T}_{\mathrm{su}}$ is the tensile force in the reinforcement at failure, taking due account of the reduction in $\sigma_{\mathrm{u}}$ with increasing temperature.

\section{Limiting Criteria}

Based on the discussions made previously in the parametric investigation, it is clear that the temperature attained at the steel reinforcement has a most significant influence on the behaviour. Additionally, for the same steel temperature, both the section thermal gradient and the difference between $\alpha_{s}$ and $\alpha_{c}$ play a role in determining the failure deflection. These effects are directly accounted for in both the full and simplified versions of the analytical model (Izzuddin and Elghazouli, 2002), and may be explicitly included in subsequent derivations. However, in the interest of practical application, the influence of any differential thermal expansion is ignored here, which is believed to be a generally conservative assumption. 
In light of the above, and considering (16) to (21), the following relationship may be derived to provide an approximate assessment of failure deflection:

$$
U=\sqrt{2 \mathrm{~L}\left(\frac{\mathrm{A}_{\mathrm{s}}\left(\sigma_{\mathrm{u}}-\sigma_{0.2}\right)}{3 \sigma_{\mathrm{b}}} \varepsilon_{\mathrm{um}}+\alpha \mathrm{t}_{\mathrm{s}} \mathrm{L}-\frac{(\alpha \nabla \mathrm{t})^{2} \mathrm{~L}^{3}}{24}\right)}
$$

in which $\sigma_{\mathrm{b}}, \sigma_{\mathrm{u}}$ and $\sigma_{0.2}$ are the temperature-dependent material properties. On the other hand, the coefficient of thermal expansion $\alpha$ can be conservatively considered as the lower of $\alpha_{c}$ and $\alpha_{s}$ if they differ within normal ranges.

In Fig. 12, the analytical results of the four cases described before and presented in Fig. 10 are compared with those obtained from (22). The failure deflection at elevated temperature is normalised to that at ambient conditions. It is evident from Fig. 12 that (22) predicts well the analytical failure deflection in (ii) and (iv) in which equal thermal expansion is considered. However, as expected, some discrepancy occurs for (i) and (iii) in which steel/concrete differential expansion exists, with (22) furnishing slightly conservative results in comparison with the analytical models.

It is important to note that thermal curvature causes a reduction in the failure deflection, as indicated in (18) and (22), due to the stretching effect under restrained conditions. This is opposed to the effective increase in deflection in unrestrained situations, as implied in previous assessments (Bailey and Moore, 2002-b).

With regard to concentration of mechanical strain in the reinforcement at the crack location, it can be shown, by close examination of (22), to be approximately represented by the following expression:

$$
\varepsilon_{\mathrm{um}} / \varepsilon_{\mathrm{vm}}=\frac{3 \sigma_{\mathrm{b}} \mathrm{L}}{\mathrm{A}_{\mathrm{s}}\left(\sigma_{\mathrm{u}}-\sigma_{0.2}\right)}
$$

where $\sigma_{\mathrm{b}}, \sigma_{\mathrm{u}}$ and $\sigma_{0.2}$ are the temperature-dependent material properties.

Using the material properties assumed in Table 4, the mechanical strain concentration (normalised to that at ambient) is plotted against the steel temperature in Fig. 13. It is indicated that $\varepsilon_{\mathrm{um}} / \varepsilon_{\mathrm{vm}}$ remains rather constant up to about $600^{\circ} \mathrm{C}$ after which it exceeds three 
times the ambient value at $800^{\circ} \mathrm{C}$. Nevertheless, as evident from (23), this directly depends on the relative variation in $\sigma_{\mathrm{b}}, \sigma_{\mathrm{u}}$ and $\sigma_{0.2}$ with temperature. Consequently, the variation of the mechanical strain concentration ratio $\left(\varepsilon_{\mathrm{um}} / \varepsilon_{\mathrm{vm}}\right)$, shown in Fig. 13, would change with assumptions different to those considered in Table 4.

In addition to the other temperature-varying material properties, (22) and (23) also depend directly on the ultimate strain of steel $\varepsilon_{\text {um }}$ which was assumed in the parametric studies conducted here to be constant with temperature. This however depends on the manufacturing process of the reinforcement. For example, in cases where the material exhibits enhanced ductility at elevated temperature, such as in cold-worked steel, the ultimate strain may increase with temperature. These effects may be directly incorporated in the above equations by considering $\varepsilon_{\text {um }}$ to be temperature-dependent.

As demonstrated above, the proposed expressions represent simplified yet sufficiently adequate relationships to predict failure. They provide realistic and efficient evaluation, which captures the influence of the salient parameters influencing the behaviour. Together with the analytical models presented in the companion paper, they represent a rational approach for the assessment of failure in restrained LRC members.

\section{CONCLUSION}

An analytical model is described in the companion paper, which represents the post-cracking ambient and elevated temperature response of axially-restrained lightly-reinforced members. The model accounts for the compressive arching and tensile catenary stages up to failure by fracture of the steel reinforcement. The scope and validity of the model are discussed through a number of illustrative examples. This paper utilises the proposed analytical model to gain an insight into the key parameters influencing the behaviour, with emphasis on the ultimate conditions associated with failure. The work presents a fundamental assessment of the fire behaviour of lightly reinforced restrained members, with direct relevance to composite floor elements, which behave in a similar manner under elevated temperature. 
A number of parametric investigations are first presented to examine the response and illustrate important behavioural patterns. The details of the type of member considered are described, and the main assumptions related to geometric and material properties are outlined. The response is first assessed at ambient conditions, which provides an essential basis before the inclusion of fire effects. It is shown that the stress-strain relationship for steel, the bond characteristics, the reinforcement area, the cross-section depth and the member length all have a significant influence on the behaviour. In particular, it is illustrated that failure can be considerably delayed in the presence of relatively low bond strength or comparatively high steel strain-hardening properties. The behaviour is then investigated under elevated temperature, which influences the response through the degradation in material properties in addition to thermal expansion effects. Various cases representing possible idealised fire conditions are examined to illustrate the importance of thermal expansion and thermal curvature.

The parametric studies identify a number of salient parameters that should be accounted for in a realistic examination of failure. These are considered in a more focused assessment of ultimate conditions aimed at providing a practical approach for failure prediction. Simplified expressions are derived based on the findings of this study, which capture the influence of the main material, geometric and temperature effects. They provide an evaluation of the strain and deflection levels corresponding to the fracture of reinforcement at ambient and elevated temperature, which may be utilised in future numerical and design studies. Even in the absence of a detailed assessment of temperature-dependent material properties, observation of these expressions enables decisions on realistic and conservative assumptions. With further experimental and analytical verification, covering other loading and boundary conditions, the work presented in this investigation can contribute to the provision of appropriate limiting criteria with a view to establishing more rational performance-based fire design provisions.

\section{ACKNOWLEDGEMENT}

The authors would like to acknowledge the support provided by the UK EPSRC for this work under grant GR/L96523. 


\section{REFERENCES}

1. ACI Manual of Concrete Practice, (1999), Part 3, American Concrete Institute, Report ACI 224.2R-92, Cracking of Concrete Members in Direct Tension, 224.2R/1$224.2 \mathrm{R} / 12$.

2. Bailey, C. G., White, D. S. and Moore, D. B., The Tensile Membrane Action of Unrestrained Composite Slabs under Fire Conditions, Engineering Structures, 22(2000), 1583-1595.

3. Bailey, C.G., and Moore D.B. (2000-a), "The Structural Behaviour of Steel Frames with Composite Floor Slabs Subject to Fire - Part 1: Theory", Struct. Eng., 78(11), pp. $19-27$.

4. Bailey, C.G., and Moore D.B. (2000-b), "The Structural Behaviour of Steel Frames with Composite Floor Slabs Subject to Fire - Part 2: Design”, Struct. Eng., 78(11), pp. $28-33$

5. Bosco, C., Carpinteri, A., and Debernardi, P.G. (1990), "Minimum Reinforcement in High-Strength Concrete”, J. Struct. Engrg., ASCE, 116(2), pp. 427-437.

6. Buchanan, A. H. (2001). "Structural Design for Fire Safety", Wiley.

7. Elghazouli, A.Y., and Izzuddin, B.A. (2000), "Response of Idealised Composite Beam-Slab Systems under Fire Conditions”, J. Const. Steel Res., 56(3), pp. 199-224.

8. Elghazouli, A.Y., and Izzuddin, B.A. (2001), “Analytical Assessment of the Structural Performance of Composite Floors Subject to Compartment Fires”, Fire Safety J., 36, pp. 769-793.

9. EC2, (1995) Eurocode 2, Design of Concrete Structures, ENV1992-1-2: 1996, Part1.2 General Rules - Structural Fire Design., European Committee for Standardisation, CEN.

10. EC4, (1995), Eurocode 4, Design of Composite Steel and Concrete Structures, ENV 1994-1-2, Part1.2 General Rules - Structural Fire Design., European Committee for Standardisation, CEN.

11. Gillie, M., Usmani, A.S., and Rotter, J.M. (2001), “A Structural Analysis of the First Cardington Test”, J. Constr. Steel Res., 57, pp. 581-601. 
12. Huang, Z. H., Burgess, I. W. and Plank, R. J. (1999), "Nonlinear Analysis of Reinforced Concrete Slabs Subjected to Fire", American Concrete Institute, Structural Journal, 96(1):127-35.

13. Izzuddin, B.A. and Elghazouli, A.Y. (2002), "Failure of Lightly Reinforced Concrete Members under Fire - Part I: Analytical Modelling”, Companion Paper.

14. Izzuddin, B.A., Elghazouli, A.Y., and Tao, X.Y. (2002), "Realistic Modelling of Composite Floor Slabs under Fire Conditions", Proc. $15^{\text {th }}$ ASCE Engineering Mechanics Conference, New York, USA.

15. Johnson, P. F. (1998), "International Developments in Fire Engineering of Steel Structures", J. Constr. Steel Res., 46(1-3), Paper No. 169.

16. Kirby, B. R. (1997), "British Steel Technical European Fire Test Programme Design, Construction and Results”, In: Armer, G., O’Dell, T. editors. Fire, Static and Dynamic Tests of Building Structures. London: Spon.

17. Neville, A.M. (1995). "Properties of Concrete", Longman.

18. O’Connor, M.A., and Martin, D.M. (1998), "Behaviour of a Multi-Storey Steel Framed Building Subjected to Fire Attack", J. Constr. Steel Res., 46(1-3), Paper No. 169.

19. Park, R. and Gamble, W. L. (2000). "Reinforced Concrete Slabs", Second Edition, Wiley.

20. Park, R., and Paulay, T. (1975), "Reinforced Concrete Structures", John Wiley \& Sons.

21. Robinson, J. (1998), "Fire - A Technical Challenge and a Market Oppotunity", J. Constr. Steel Res., 46(1-3), Paper No. 415.

22. Royles, R., Morley, P. D. and Khan, M. R. (1982). "The Behaviour of Reinforced Concrete at Elevated Temperatures with particular Reference to Bond Strength", In: Bond in Concrete, Edited by Bartos, P., Applied Science Publishers, 217-228.

23. Sager, H. and Rostasy, F. S. (1982). "The Effect of Elevated Temperature on the Bond Behaviour of Embeded Reinforcing Bars, In: Bond in Concrete", Edited by Bartos, P., Applied Science Publishers, 206-216.

24. Wang, Y.C., Lennon, T., and Moore, D.B. (1995), "The Behaviour of Steel Frames Subject to Fire", J. Constr. Steel Res., 35, pp. 291-322. 


\section{TABLES}

\begin{tabular}{|l|l|}
\hline Member Configuration & Ambient material properties \\
\hline $\mathrm{L}=1500 \mathrm{~mm}$ & $\mathrm{E}_{\mathrm{s}}=210 \mathrm{E} 3 \mathrm{~N} / \mathrm{mm}^{2}$ \\
\hline $\mathrm{h}=60 \mathrm{~mm}$ & $\mathrm{a}_{\mathrm{s}}=5.3 \mathrm{E}-71, \mathrm{n}_{\mathrm{s}}=25$ \\
\hline $\mathrm{b}=200 \mathrm{~mm}$ & $\varepsilon_{\mathrm{pu}}=0.15$ \\
\hline $\mathrm{A}_{\mathrm{s}}=30 \mathrm{~mm}^{2}$ & $\sigma_{\mathrm{u}}=600 \mathrm{~N} / \mathrm{mm}^{2}$ \\
\hline$\rho=0.25 \%$ & $\mathrm{E}_{\mathrm{c}}=30 \mathrm{E} 3 \mathrm{~N} / \mathrm{mm}^{2}$ \\
\hline$d_{\mathrm{s}}=30 \mathrm{~mm}$ & $\sigma_{\mathrm{b}}=40 \mathrm{~N} / \mathrm{mm}^{2}$ \\
\hline
\end{tabular}

Table 1: Details of the control model

\begin{tabular}{|l|c|c|c|c|}
\hline & $\mathrm{a}_{\mathrm{s}}, \mathrm{n}_{\mathrm{s}}$ & $\varepsilon_{\mathrm{pu}}$ & $\sigma_{\mathrm{u}}\left(\mathrm{N} / \mathrm{mm}^{2}\right)$ & $\sigma_{0.2}\left(\mathrm{~N} / \mathrm{mm}^{2}\right)$ \\
\hline Type S1 (control) & $5.3 \mathrm{E}-71,25$ & 0.15 & 600 & 505 \\
\hline Type S2 & $1.5 \mathrm{E}-26,9$ & 0.15 & 600 & 372 \\
\hline Type S3 & $2.0 \mathrm{E}-15,5$ & 0.15 & 600 & 253 \\
\hline
\end{tabular}

Table 2: Variation in steel material law

\begin{tabular}{|l|c|c|c|c|c|}
\hline $\mathrm{h}(\mathrm{mm})$ & $\mathrm{A}_{\mathrm{s}}\left(\mathrm{mm}^{2}\right)$ & $\sigma_{\mathrm{b}}(\mathrm{N} / \mathrm{mm})$ & $\mathrm{d}_{\mathrm{s}}(\mathrm{mm})$ & $\mathrm{h}_{\mathrm{c}}(\mathrm{mm})$ & $\rho(\%)$ \\
\hline 30 & 15 & 20 & 15 & 15 & 0.25 \\
\hline 60 (control) & 30 & 40 & 30 & 30 & 0.25 \\
\hline 90 & 45 & 60 & 45 & 45 & 0.25 \\
\hline 120 & 60 & 80 & 60 & 60 & 0.25 \\
\hline
\end{tabular}

Table 3: Parameters used in the study of cross-section depth 


\begin{tabular}{|l|ccc|}
\hline Temperature $\left({ }^{\circ} \mathrm{C}\right)$ & $0-100$ & 700 & 1200 \\
$\mathrm{E}_{\mathrm{s}}$ (elevated/ambient) & 1.0 & 0.1 & 0 \\
\hline Temperature $\left({ }^{\circ} \mathrm{C}\right)$ & 0 & 600 & 1200 \\
$\mathrm{E}_{\mathrm{c}}$ (elevated/ambient) & 1.0 & 0.1 & 0 \\
\hline Temperature $\left({ }^{\circ} \mathrm{C}\right)$ & $0-300$ & 1000 & 1200 \\
$\sigma_{\mathrm{b}}($ elevated/ambient) & 1.0 & 0.1 & 0 \\
\hline Temperature $\left({ }^{\circ} \mathrm{C}\right)$ & $0-400$ & 800 & 1200 \\
$\sigma_{\mathrm{u}}$ (elevated/ambient) & 1.0 & 0.1 & 0 \\
\hline
\end{tabular}

Table 4: Variation of material properties with temperature 


\section{NOTATION}

$\mathrm{a}_{\mathrm{s}} \quad$ : material parameter for Ramberg-Osgood steel model, function of temperature

$\mathrm{A}_{\mathrm{s}} \quad$ : area of steel reinforcement

b $\quad$ : cross-section width

$\mathrm{C}_{\mathrm{c}}$ : resultant compressive axial force in concrete at crack location

$\mathrm{d}_{\mathrm{s}} \quad$ : distance of steel reinforcement from bottom fibre

$\mathrm{E}_{\mathrm{c}} \quad$ : elastic Young's modulus of concrete, function of temperature $\mathrm{t}_{\mathrm{c}}$

$\mathrm{E}_{\mathrm{s}} \quad$ : elastic Young's modulus of steel, function of temperature $t_{s}$

h $\quad$ : depth of cross-section

$h_{c} \quad$ : assumed distance of contact point from steel reference line

L : half span of member

$\mathrm{L}_{\mathrm{d}} \quad$ : length on no bond-slip region

$\mathrm{M}_{\mathrm{c}} \quad$ : resultant moment of $\mathrm{C}_{\mathrm{c}}$ about steel reference line

$\mathrm{n}_{\mathrm{s}} \quad$ : material parameter for Ramberg-Osgood steel model

P : half of member midspan load

$\mathrm{t}_{\mathrm{b}} \quad$ : bottom-fibre temperature

$\mathrm{t}_{\mathrm{c}} \quad$ : temperature of concrete

$\mathrm{t}_{\mathrm{s}} \quad$ : temperature of steel reinforcement

$\mathrm{T}_{\mathrm{s}} \quad$ : tensile force in reinforcement at crack location

$\mathrm{T}_{\mathrm{su}} \quad$ : ultimate tensile force in reinforcement at rupture

$\mathrm{t}_{\mathrm{t}} \quad$ : top-fibre temperature

U : midspan transverse displacement

$\mathrm{V} \quad$ : shear force at crack location, ignoring concrete mechanical shortening 
$\mathrm{x}_{\mathrm{d}} \quad$ : length of bond-slip region

$\alpha_{c} \quad$ : coefficient of thermal expansion for steel

$\alpha_{\mathrm{s}} \quad$ : coefficient of thermal expansion for steel

$\beta_{\varepsilon} \quad$ : parameter related to mechanical strain concentration

$\nabla \mathrm{t} \quad$ : thermal gradient over cross-section

$\delta_{\mathrm{c} 0} \quad$ : unrestrained axial pull-in of concrete due to thermal bowing

$\Delta_{\mathrm{S}} \quad$ : extension of steel reinforcement along thermally curved reference line

$\varepsilon_{\text {an }} \quad:$ axial generalised strain in no bond-slip region

$\varepsilon_{\mathrm{ct}} \quad:$ thermal strain of concrete

$\varepsilon_{\mathrm{pu}} \quad:$ plastic rupture strain of steel

$\varepsilon_{\mathrm{sm}} \quad:$ mechanical strain of steel

$\varepsilon_{\text {st }} \quad:$ thermal strain of steel

$\varepsilon_{\mathrm{um}} \quad:$ ultimate mechanical strain of steel

$\varepsilon_{\mathrm{vm}} \quad$ : average mechanical strain of steel at failure, over the length $\mathrm{L}$

$\theta_{\mathrm{t} 0} \quad$ : local rotations at crack location and right support due to thermal curvature

$\rho \quad$ : reinforcement ratio

$\sigma_{0.2} \quad$ : proof stress of steel, corresponding to $0.2 \%$ plastic strain

$\sigma_{b} \quad$ : bond strength in units of force per length, function of temperature $t_{s}$

$\sigma_{\mathrm{c}} \quad:$ stress of concrete

$\sigma_{\mathrm{s}} \quad:$ stress of steel, typically in bond-slip region

$\sigma_{\text {sn }} \quad:$ stress of steel in no bond-slip region, function of temperature $t_{s}$

$\sigma_{u} \quad$ : ultimate stress of steel, function of temperature $t_{s}$

$\psi_{\mathrm{U}} \quad$ : parameter related to normalised failure deflection at ambient 


\section{LIST OF FIGURES}

Figure 1 Structural Plan of a composite Floor

Figure 2 Geometry and loading details of the lightly reinforced member
(a) Layout of cracked member
(b) Member cross-section
(c) Partial member configuration

Figure 3 Results of control analysis
(a) Load-deflection relationship
(b) Slip length versus deflection
(c) Steel stress versus deflection

Figure 4 Influence of steel constitutive characteristics
(a) Stress-strain relationship
(b) Load-deflection relationship
(c) Slip length versus deflection

Figure 5 Influence of bond strength
(a) Load-deflection relationship
(b) Slip length versus deflection

Figure 6 Influence of reinforcement ratio
(a) Load-deflection relationship
(b) Slip length versus deflection

Figure 7 Influence of reinforcement ratio
(a) Load versus deflection
(b) Slip length versus deflection

Figure 8 Influence of partial member length

(a) Load versus deflection 
(b) Slip length versus deflection

Figure 9 Response under various bottom temperatures for general case with gradient and unequal expansion
(a) Load-deflection curves
(b) Slip length versus deflection 


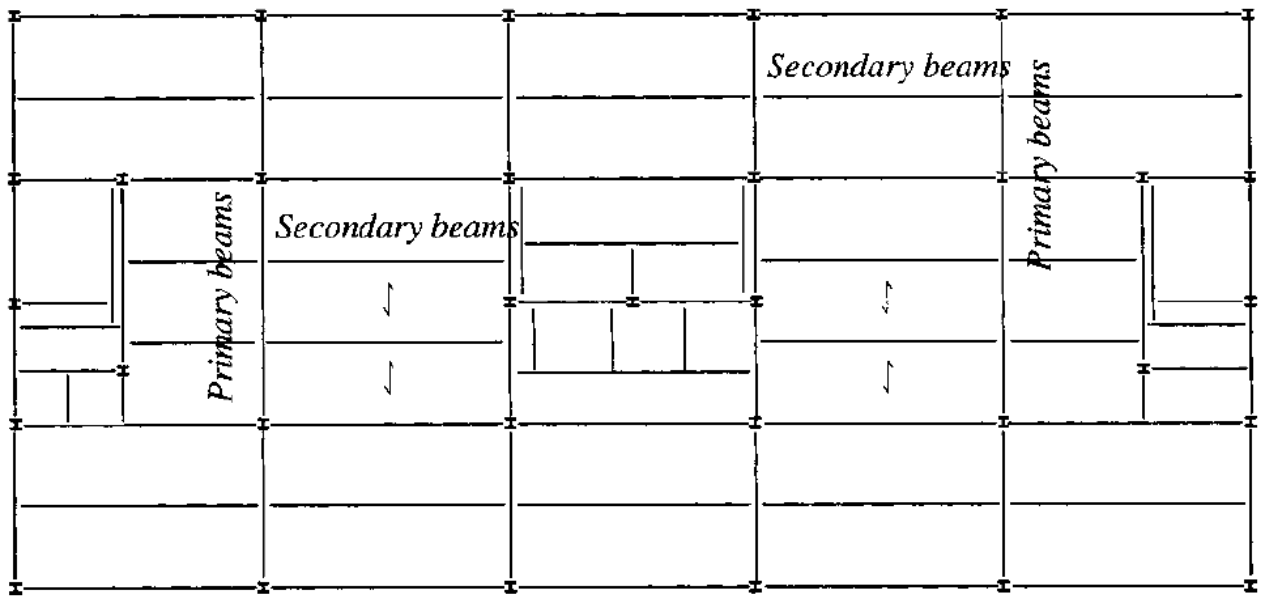

Figure 1 Structural Plan of a composite Floor

Elghazouli \& Izzuddin: Failure of Lightly Reinforced Concrete Members ...: Part II 


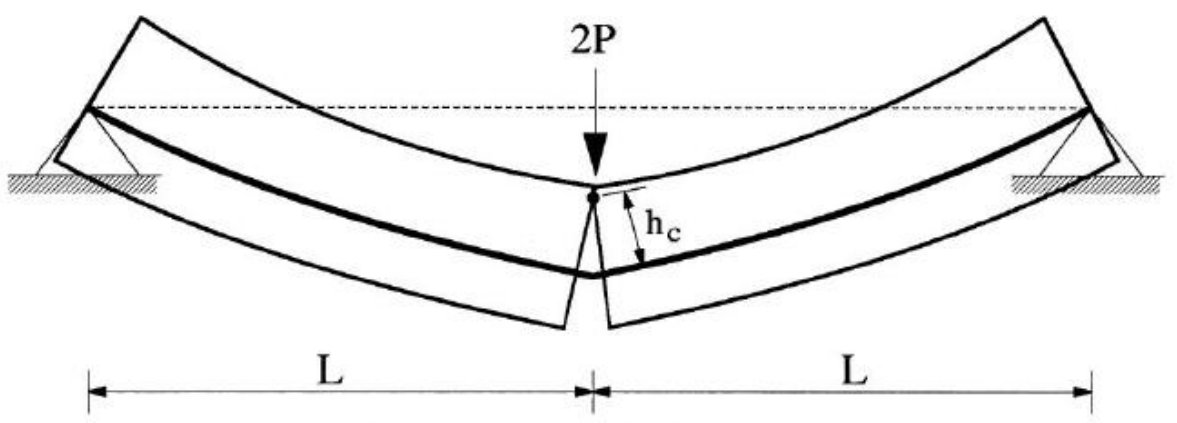

(a) Layout of cracked member

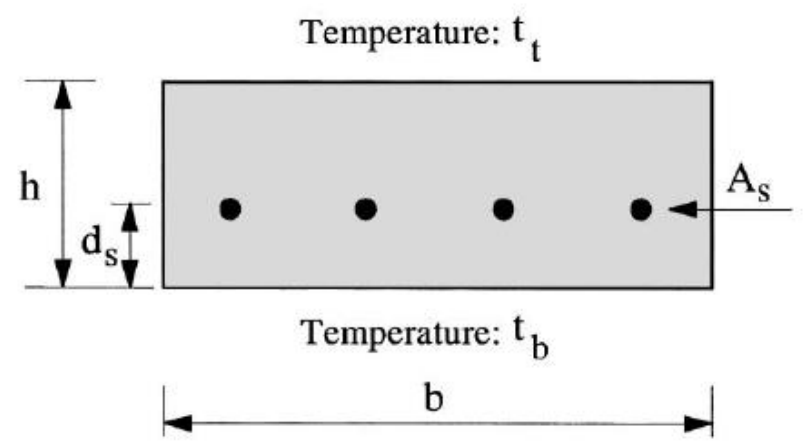

(b) Member cross-section

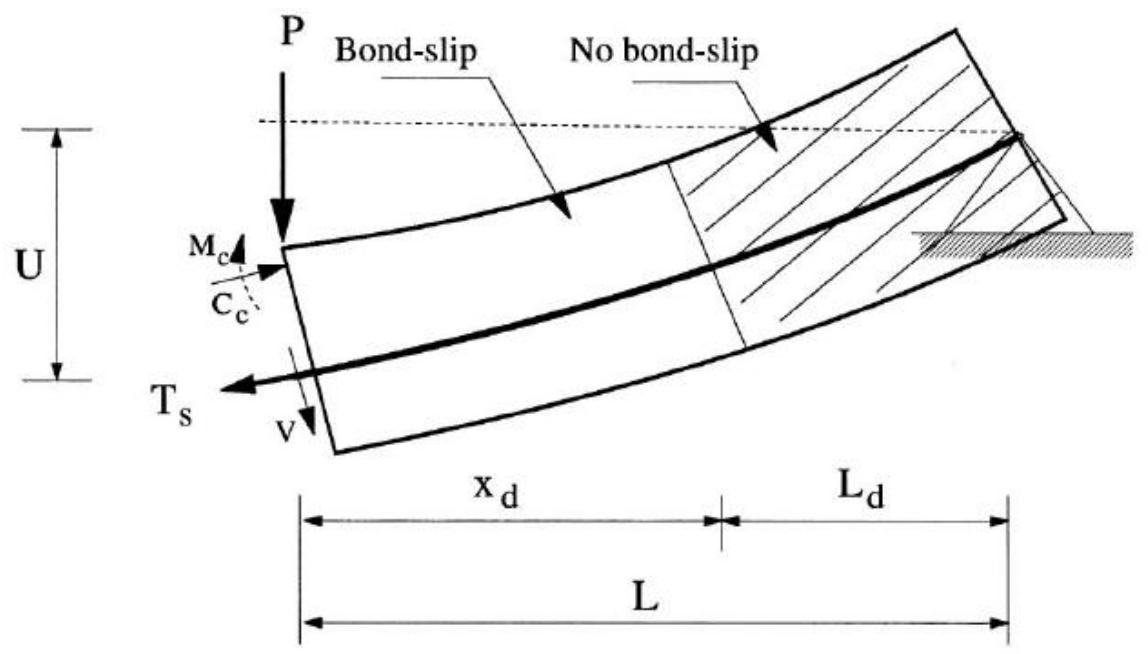

(c) Partial member configuration

Figure 2 Geometry and loading details of the lightly reinforced member 


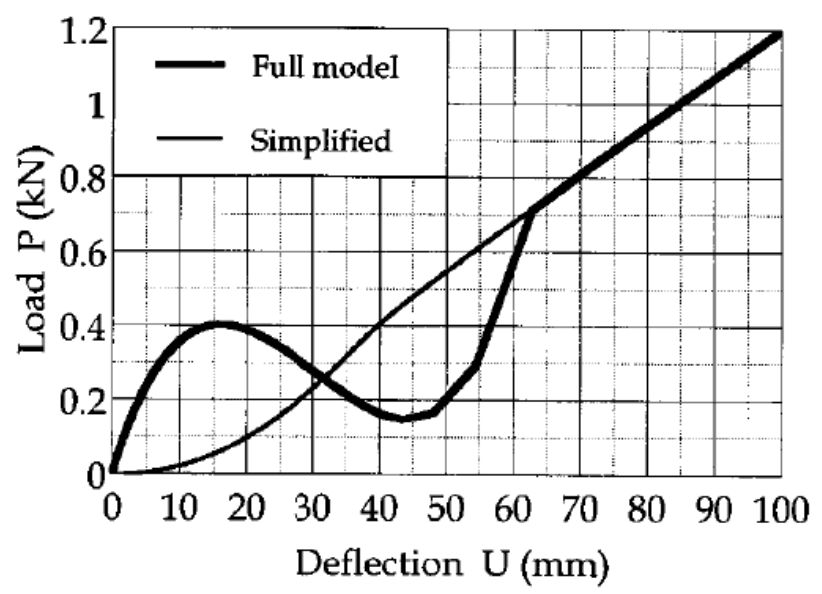

(a) Load-deflection relationship

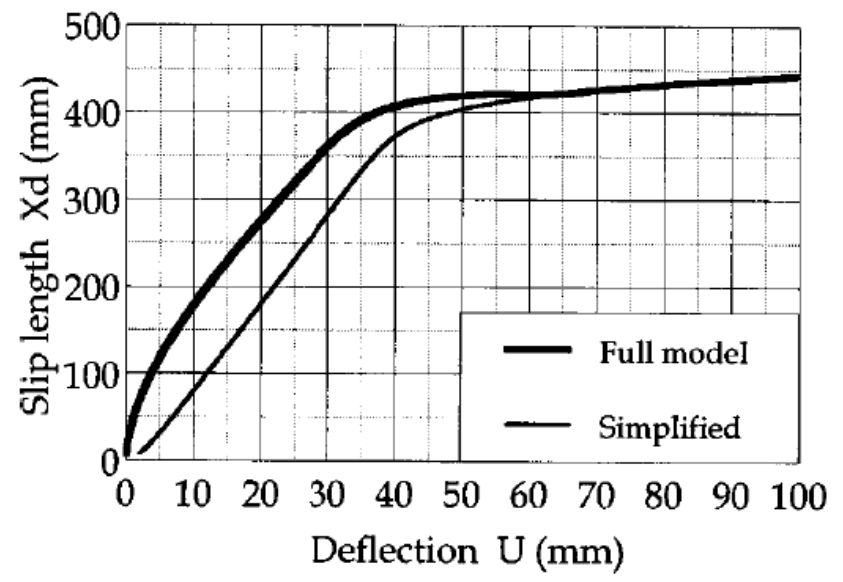

(b) Slip length vesrsus deflection

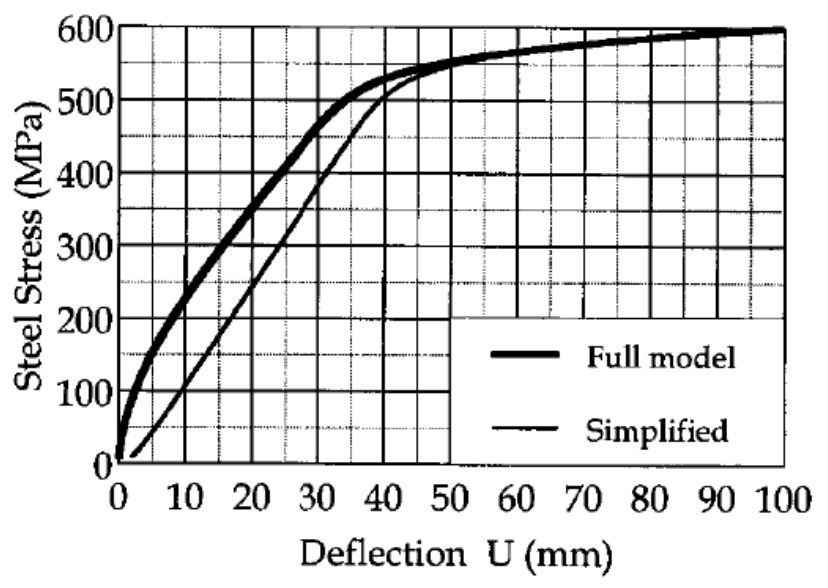

(c) Steel stress versus deflection

Figure 3 Results of control analysis 


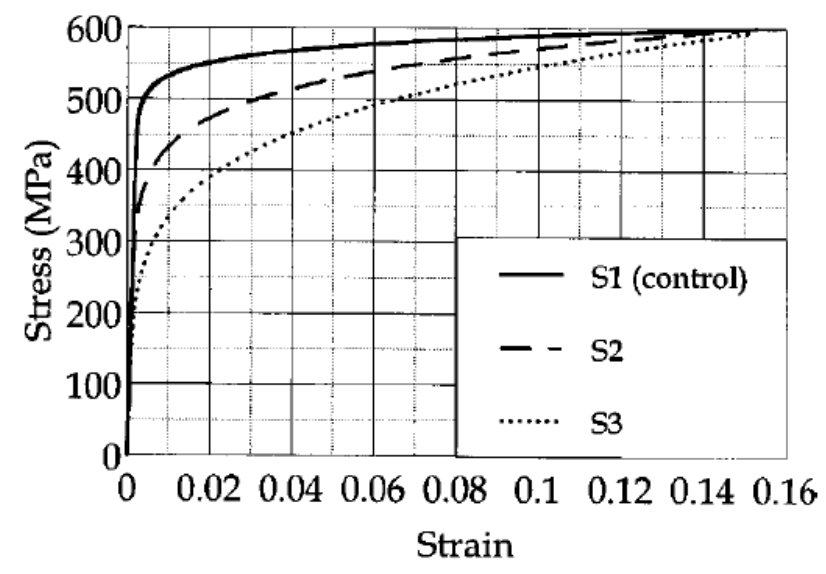

(a) Stress-strain relationship

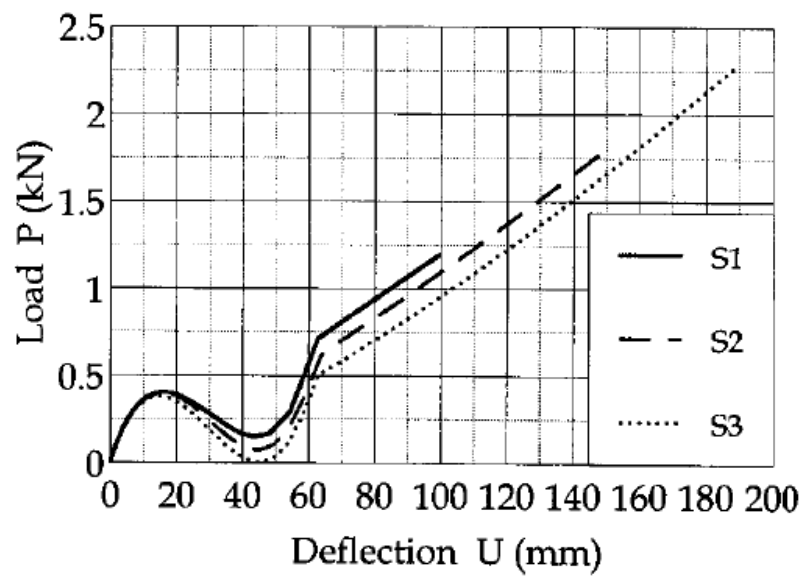

(b) Load-deflection relatiosnhip

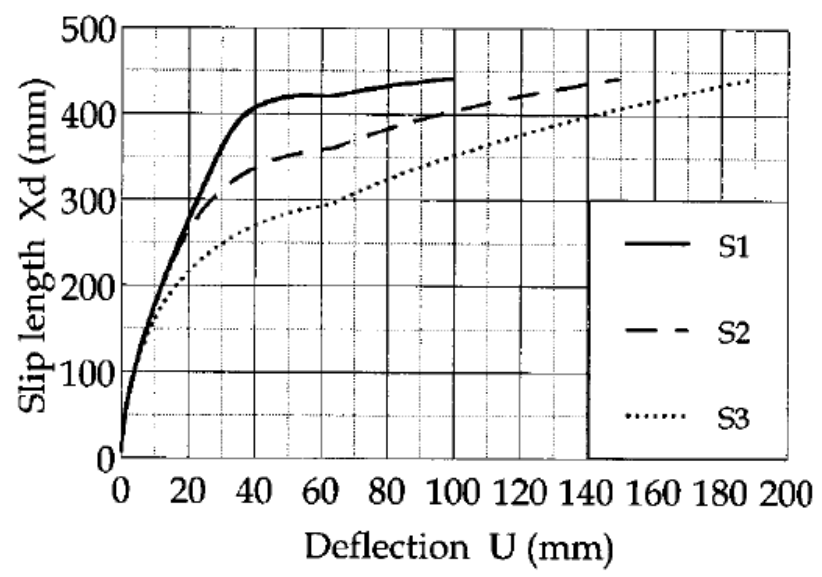

(c) Slip length versus deflection

Figure 4 Influence of steel constitutive characteristics 


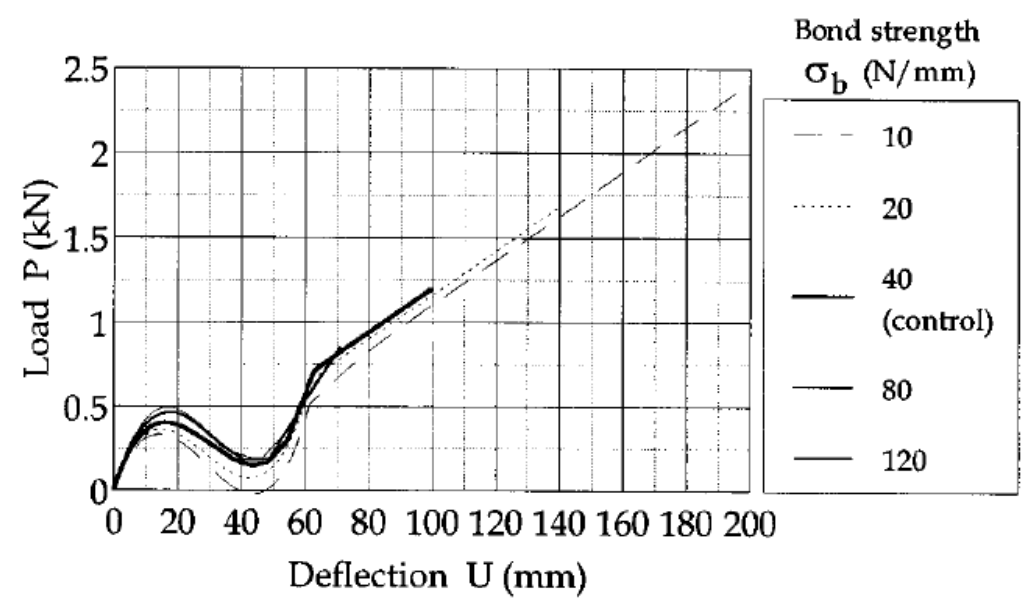

(a) Load-deflection relationship

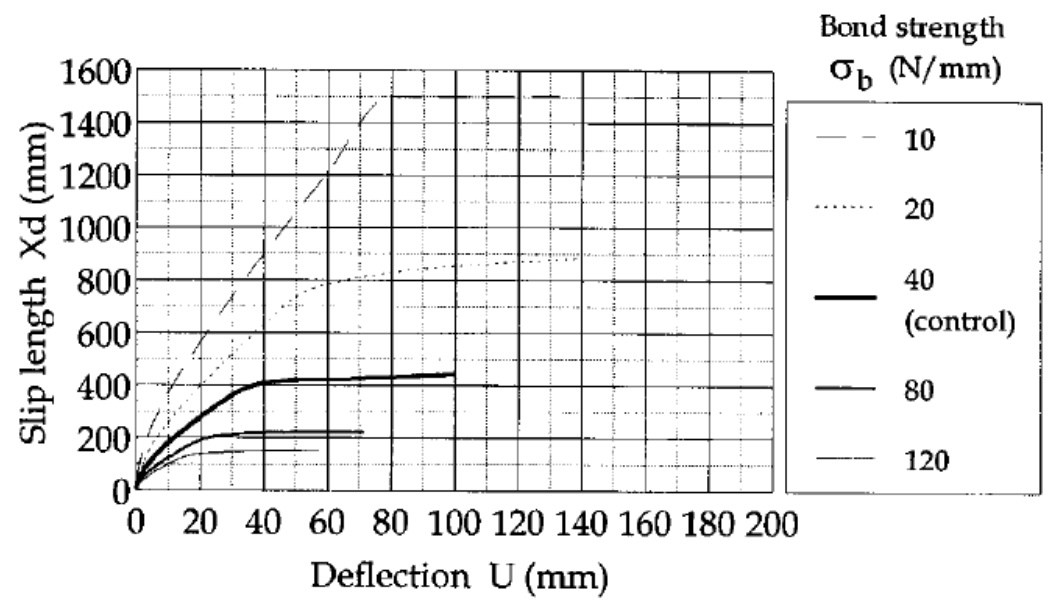

(b) Slip length versus deflection

Figure 5 Influence of bond strength 


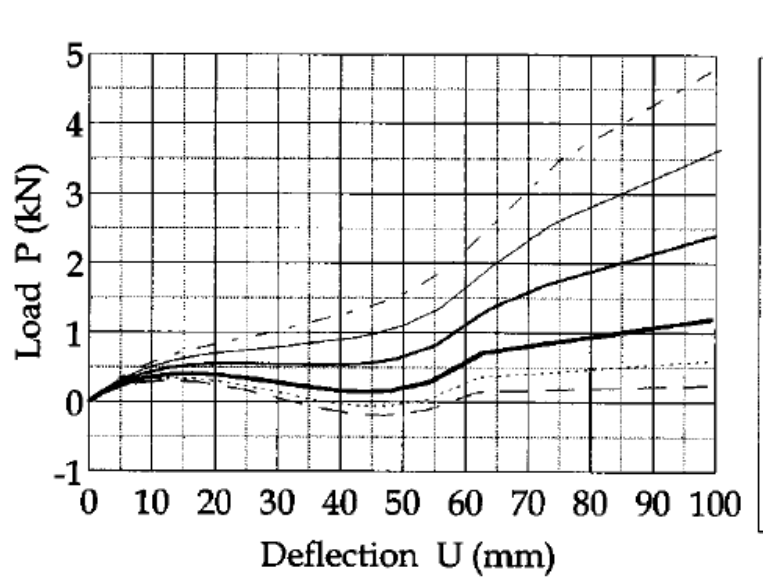

Reinforcement

ratio $(\rho)$

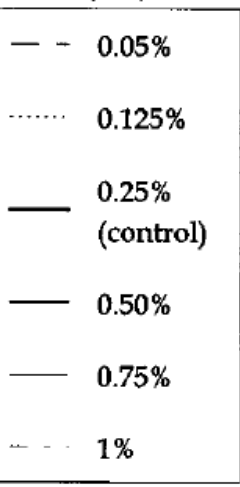

(a) Load-deflection relatiosnhip

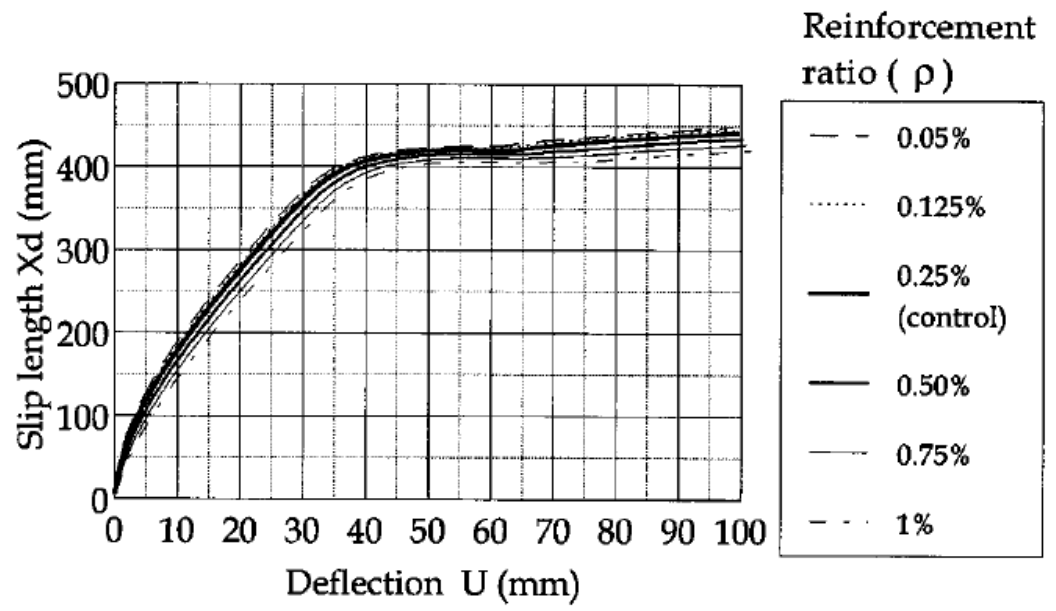

(b) Slip length versus deflection

Figure 6 Influence of reinforcement ratio

Elghazouli \& Izzuddin: Failure of Lightly Reinforced Concrete Members ...: Part II 


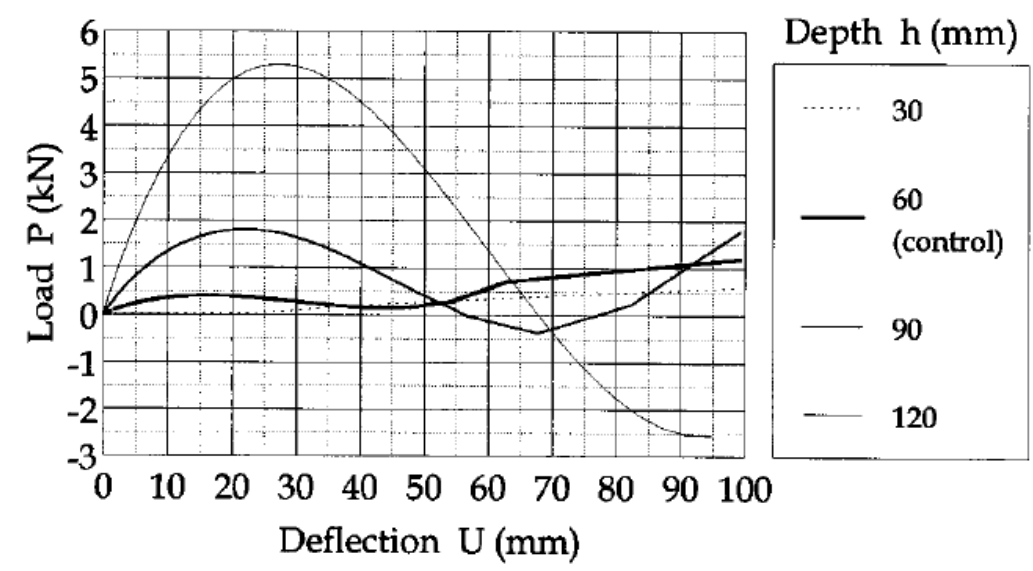

(a) Load versus deflection

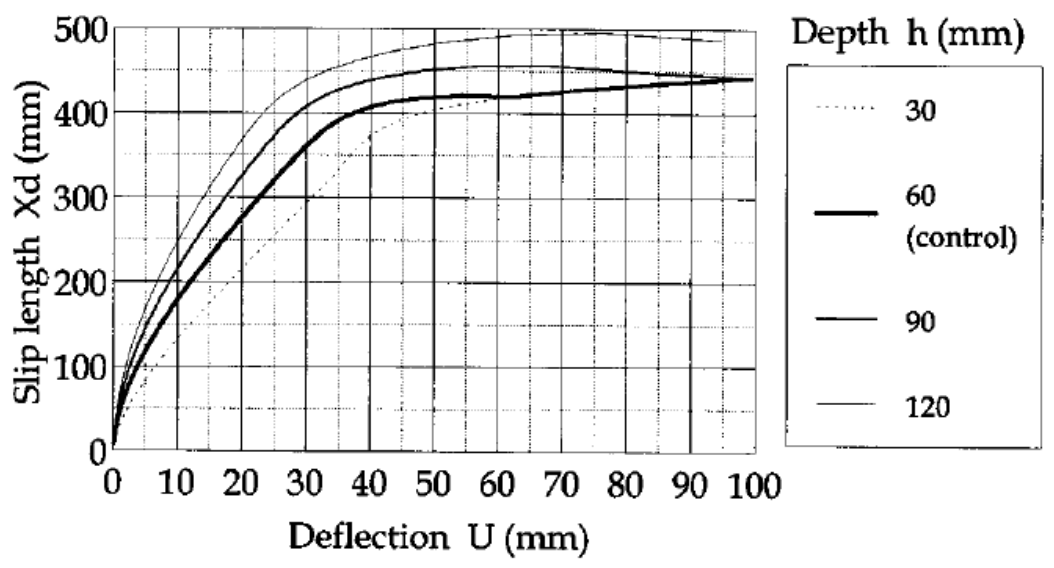

(b) Slip length versus deflection

Figure $7 \quad$ Influence of depth 


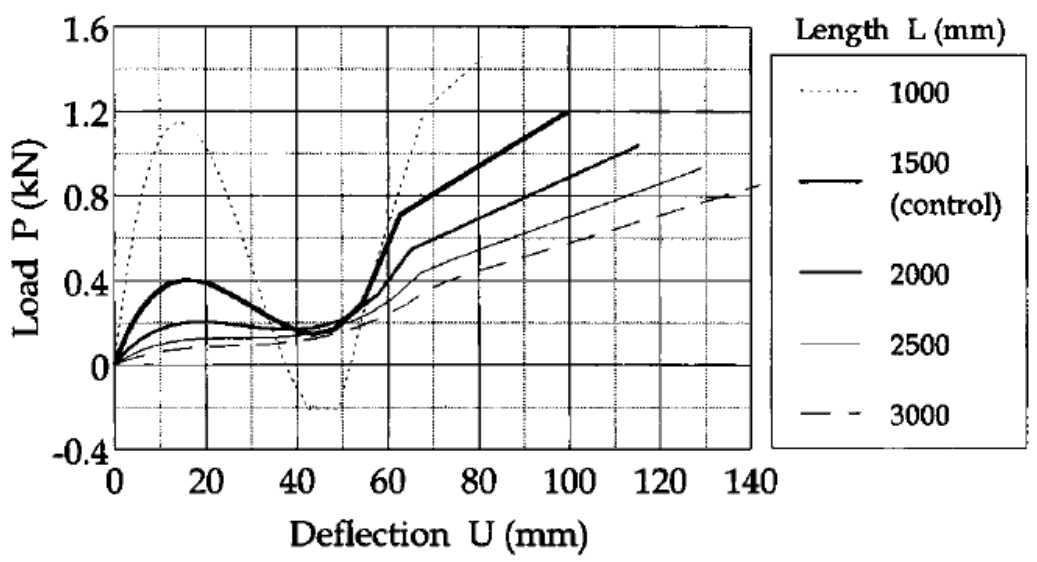

(a) Load versus deflection

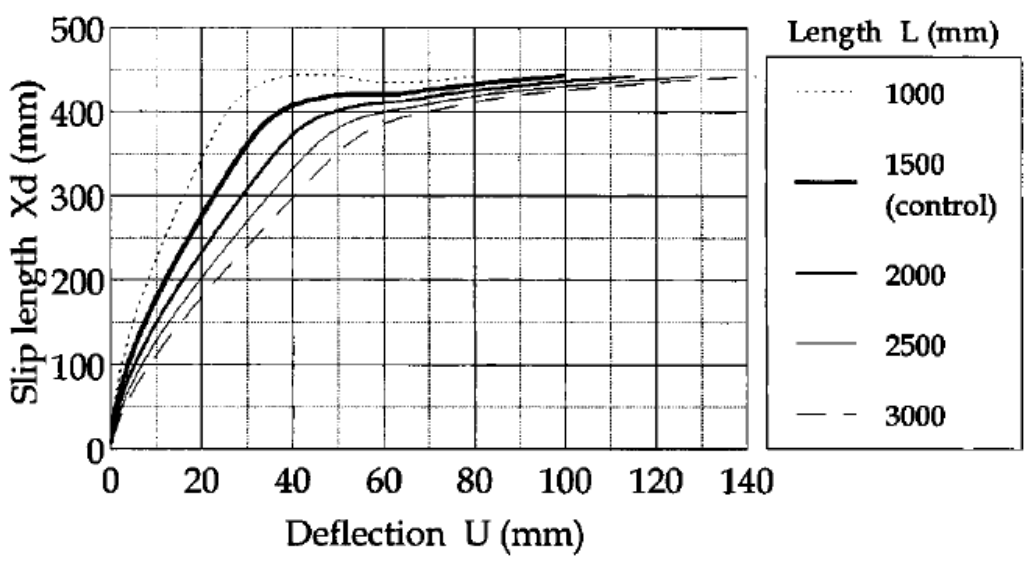

(b) Slip length versus deflection

Figure 8 Influence of partial member length 


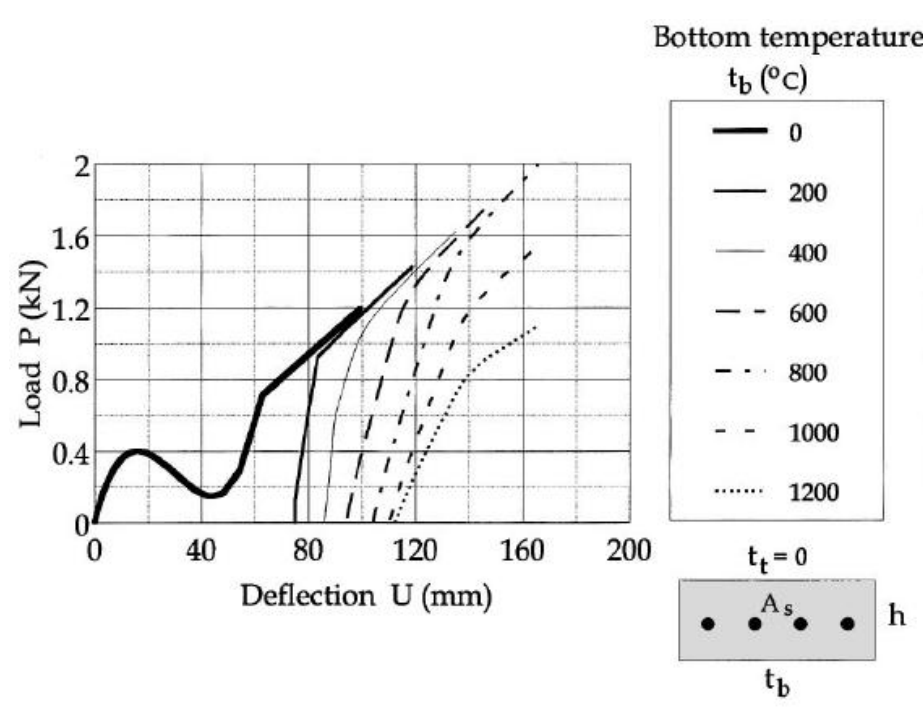

(a) Load-deflection curves

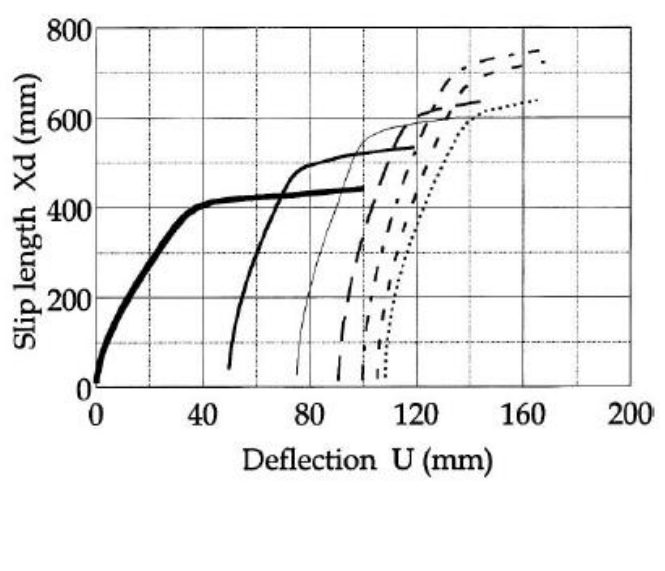

(b) Slip length versus deflection

Figure 9 Response under various bottom temperatures for general case with gradient and unequal expansion 


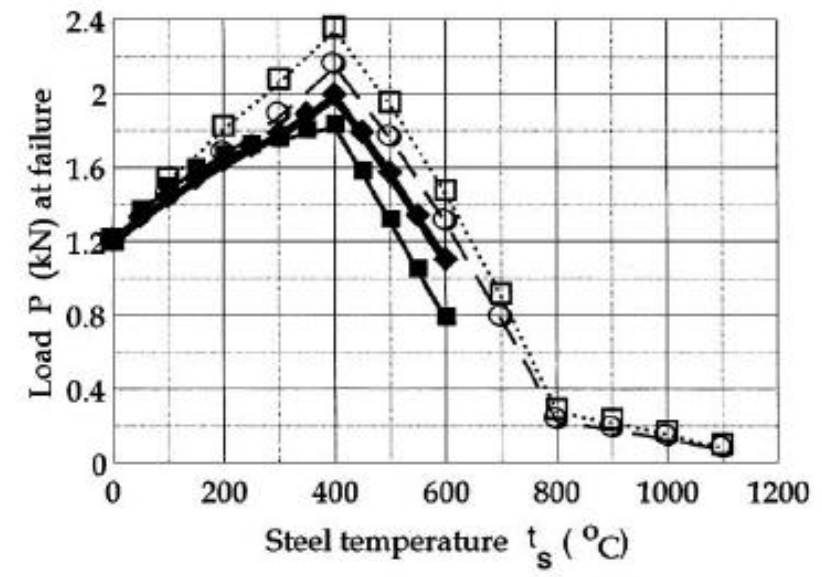

(a) Failure load versus steel temperature

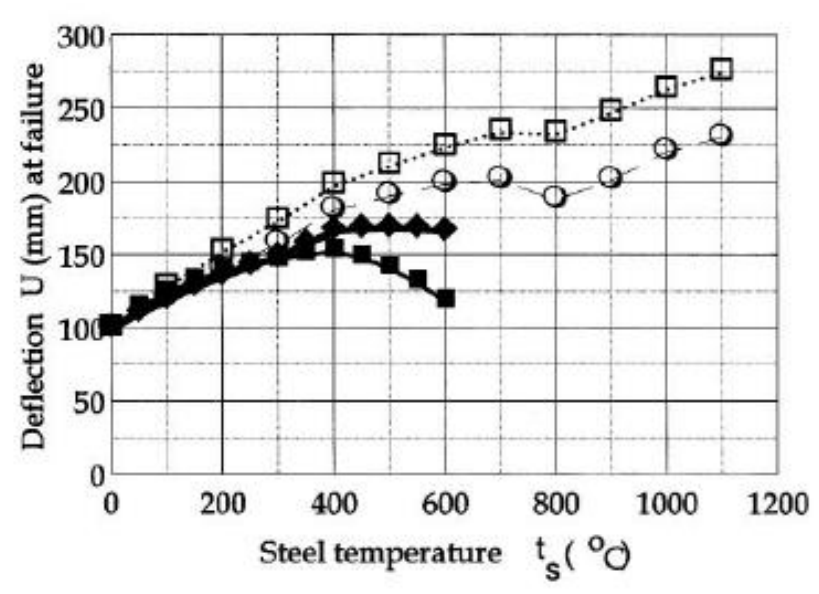

(b) Failure deflection versus steel temperature

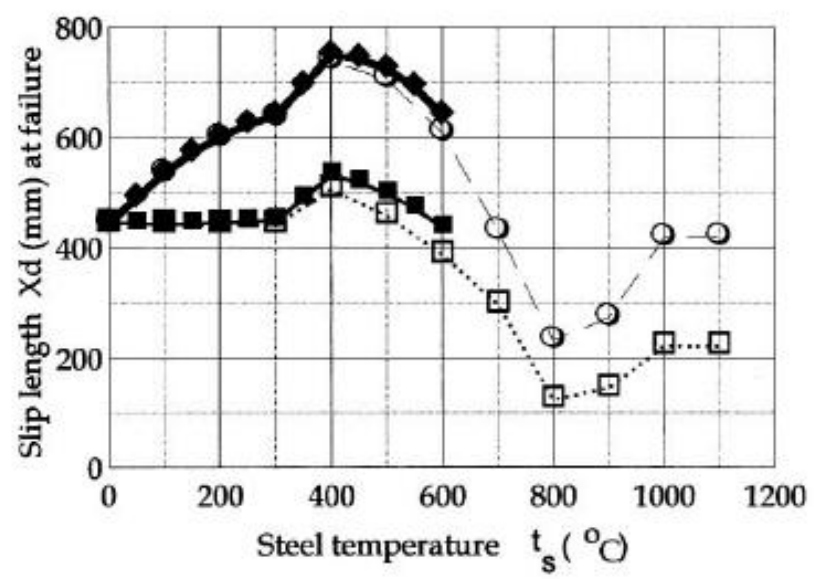

(c) Slip length versus steel temperature

$\rightarrow$ (i) $\mathrm{t}_{\mathrm{b}^{\prime}} \mathrm{t}_{\mathrm{t}}=0, \alpha_{\mathrm{s}}=14 \times 10^{-6}, \alpha_{\mathrm{c}}=8 \times 10^{-6}$
- (ii) $\mathrm{t}_{\mathrm{b}^{\prime}} \mathrm{t}_{\mathrm{t}}=0, \alpha_{\mathrm{s}}=\alpha_{\mathrm{c}}=14 \times 10^{-6}$
$\rightarrow$ (iii) $\mathrm{t}_{\mathrm{b}}=\mathrm{t}_{\mathrm{t}^{\prime}} \alpha_{\mathrm{s}}=14 \times 10^{-6}, \alpha_{\mathrm{c}}=8 \times 10^{-6}$
$\cdots$ (iv) $\mathrm{t}_{\mathrm{b}}=\mathrm{t}_{\mathrm{t}} \alpha_{\mathrm{s}}=\alpha_{\mathrm{c}}=14 \times 10^{-6}$

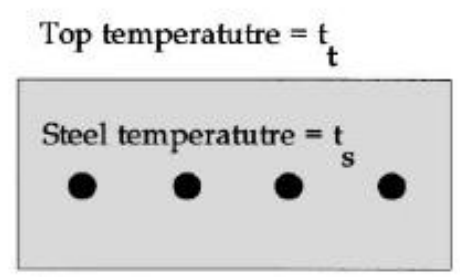

Bottom temperatutre $=t_{b}$

Figure 10 Influence of temperature gradient and differential expansion 


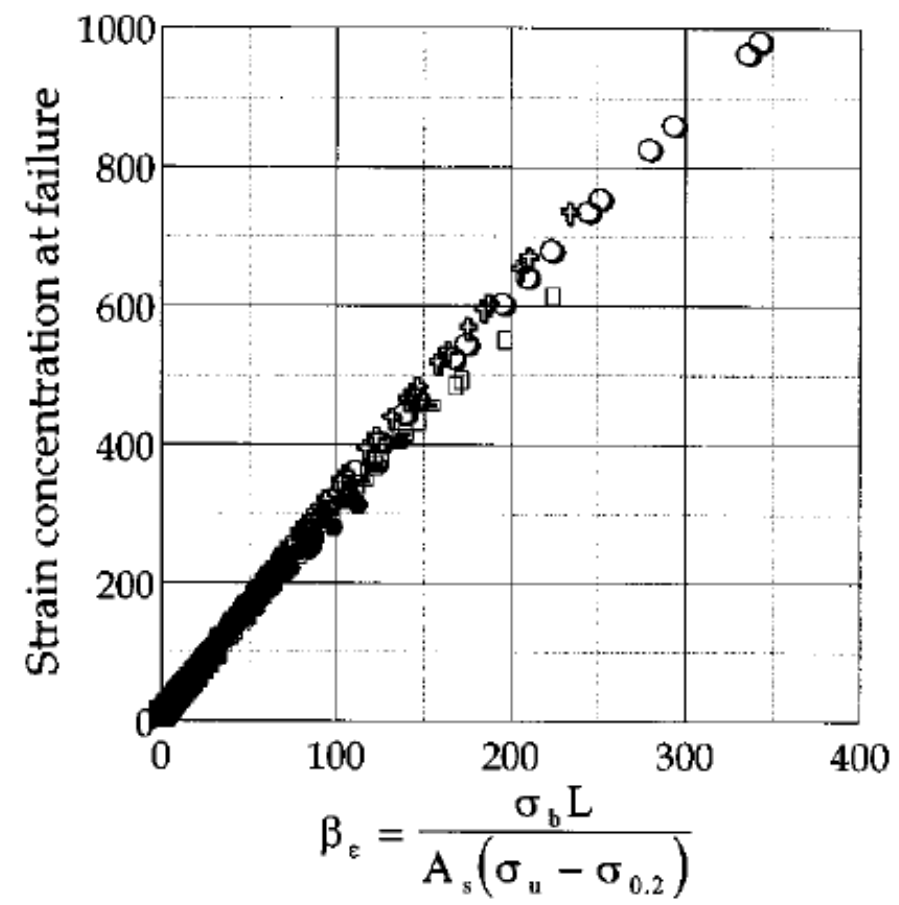

(a) Strain concentration

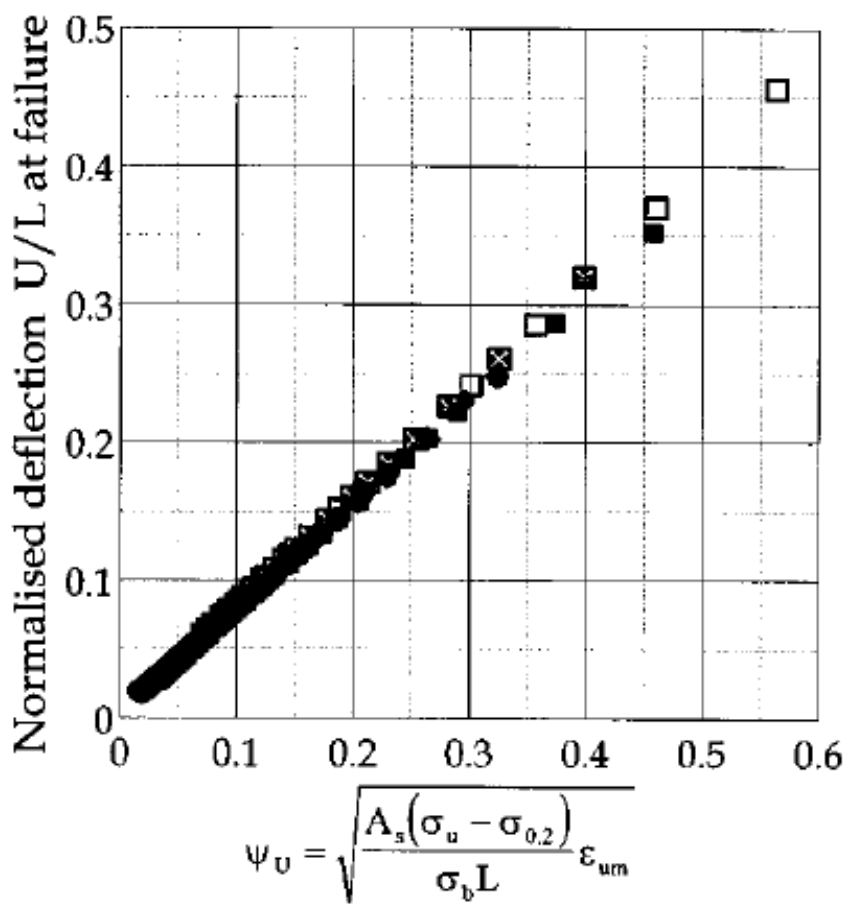

(b) Normalised deflection

Figure 11 Prediction of failure strain and deflection at ambient 
(i) $t_{b}=$ varied, $t_{t}=0, \alpha_{s}=14 \times 10^{-6}, \alpha_{c}=8 \times 10^{-6}$

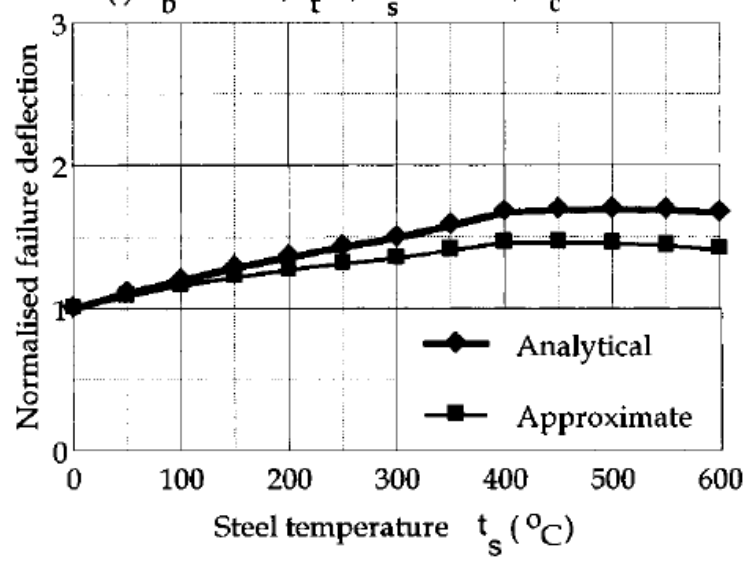

(a) Gradient with unequal expansion

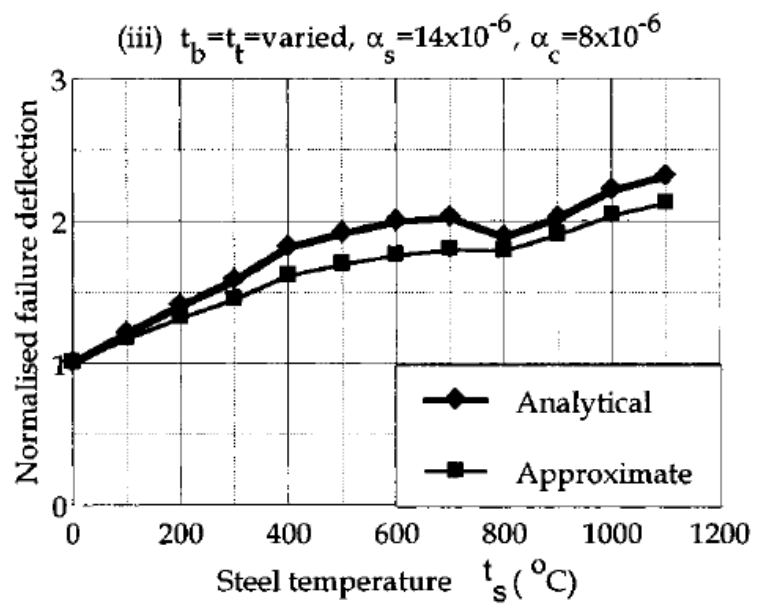

(c) No gradient with unequal expansion (ii) $t_{b}=$ varied, $t_{t}=0, \alpha_{s}=\alpha_{c}=14 \times 10^{-6}$

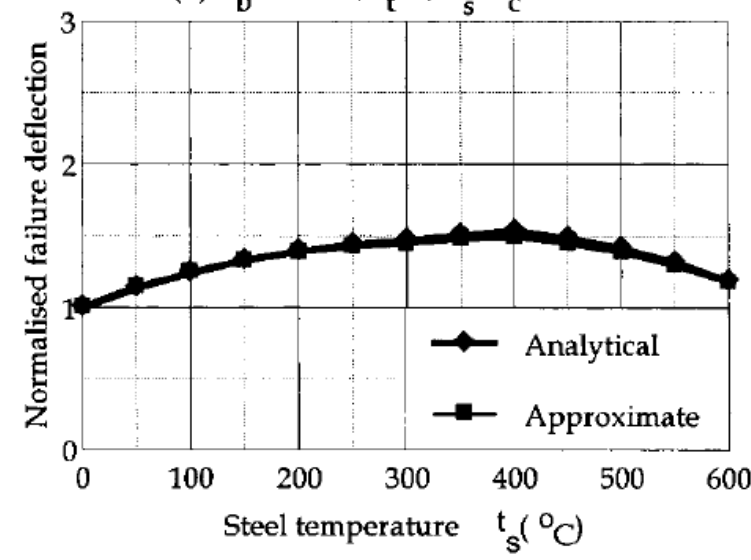

(b) Gradient with equal expansion

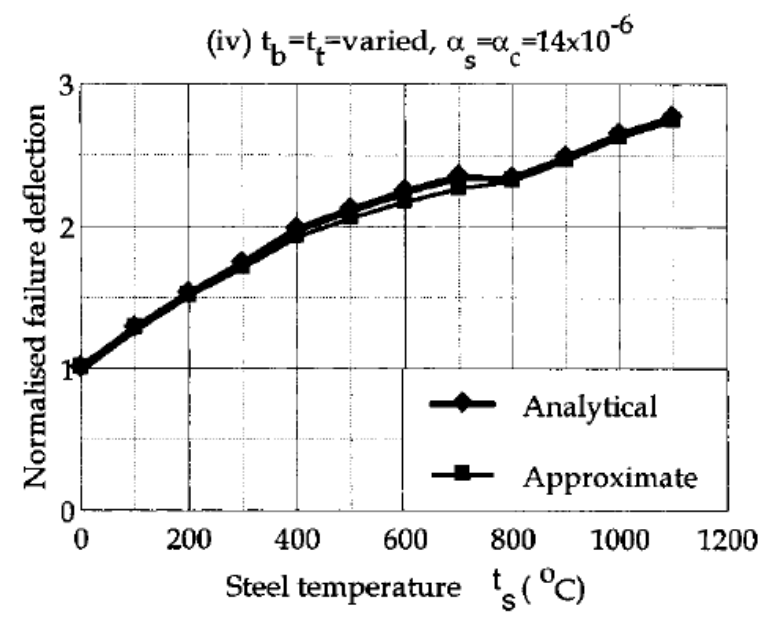

(d) No gradient with equal expansion

Figure 12 Failure deflection normalised to that at ambient 


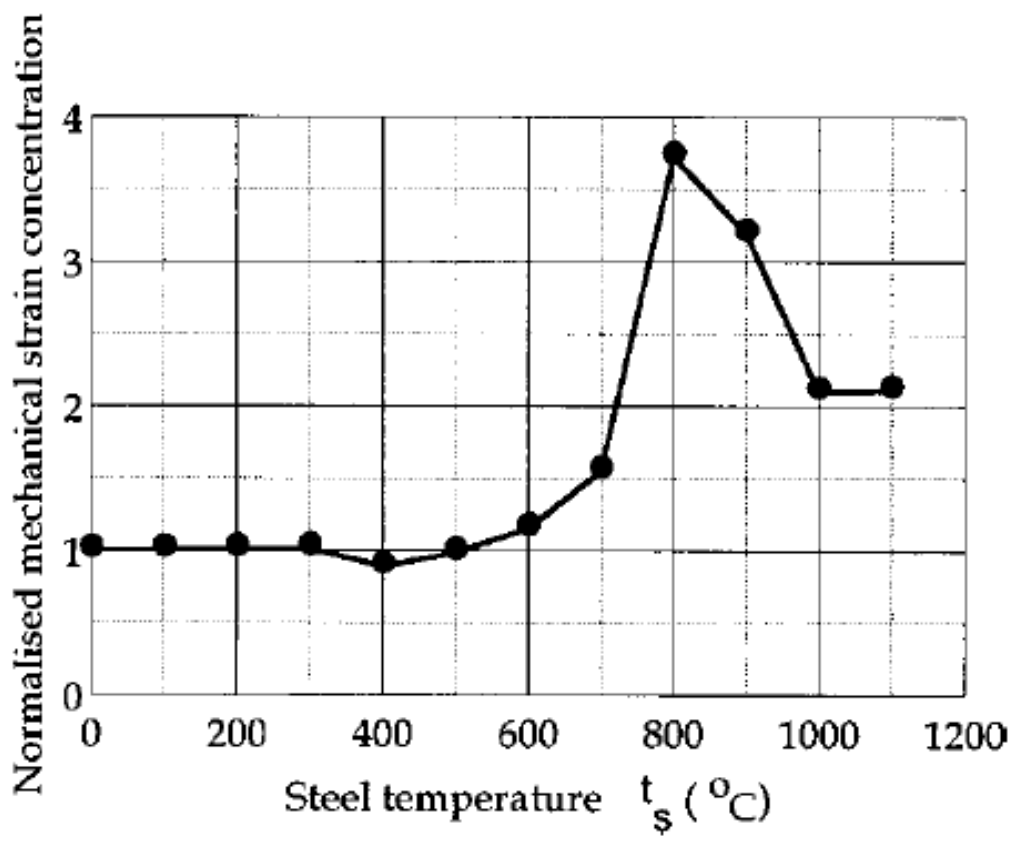

Figure 13 Mechanical strain concentration at elevated temperature normalised to that at ambient based on assumed properties 